\title{
1 Title: Regulation of vocal precision by local noradrenergic modulation of a motor nucleus
}

2

3 Running title: Noradrenergic regulation of birdsong precision

4

5 Authors: Christopher M Glaze ${ }^{1,5^{*}}$, Christina B Castelino ${ }^{1,4^{*}}$, Steve P Bibu ${ }^{1}$, Elvina Yau $^{3}$, Marc F

6 Schmidt ${ }^{1,2,3}$

$7 \quad$ *Both authors contributed equally to this work

8

$9 \quad{ }^{1}$ Biology Department, University of Pennsylvania, Philadelphia, PA 19104

$10 \quad{ }^{2}$ Neuroscience Graduate Group, University of Pennsylvania, Philadelphia, PA 19104

$11{ }^{3}$ Biological Basis of Behavior Program, University of Pennsylvania, Philadelphia, PA 19104

$12{ }^{4}$ Current Address: The Lockwood Group, Stamford, CT 06901.

13 Current Address: Department of Neuroscience, University of Pennsylvania, Philadelphia, PA 19104

14

15 Corresponding Author: Marc F Schmidt

16

Email: marcschm@sas.upenn.edu

17

18 Number of pages (39); Number of figures (6); Number of Tables (1)

19 Word count: Abstract (143); introduction (673); Discussion (1492);

20 


\section{ABSTRACT}

24 Recent theories of norepinephrine (NE) function suggest that NE modulates the

25 transition between stereotyped, goal-directed behavior and more variable exploratory

26 behaviors that facilitate learning and adaptation. We provide evidence for context

27 dependent switching by NE that is analogous to this explore/exploit strategy in the vocal system of the zebra finch (Taeniopygia guttata). Stimulation of the locus coeruleus, the major source of norepinephrine in the brain, decreases song trial-to-trial variability

30 transforming the variable, exploratory "undirected" song into song that resembles the

31 more stereotyped, exploitative "directed" song males sing to females. This behavioral

32 switch is mediated by NE acting directly on a cortical motor nucleus that integrates

33 inputs from a premotor cortical nucleus and a basal ganglia circuit necessary for vocal

34 motor learning. These findings suggest that norepinephrine can act directly on the motor system to influence the transition between exploratory and exploitative behavioral strategies. 


\section{INTRODUCTION}

Activation of the locus coeruleus (LC), through its diffuse projections, has been traditionally implicated in regulating arousal levels (Kety, 1972) and modulating neural responsiveness in sensory and learning circuits (Hasselmo et al., 1997; Berridge and Waterhouse, 2003). More recent theoretical work has suggested that LC mediated release of norepinephrine (NE) may facilitate the optimization of behavior with respect to rewards and goals by increasing the gain of neural activation functions, directly affecting the precision of action selection among a discrete set of options in learning and decision-making tasks (Aston-Jones and Cohen, 2005a). According to this proposal, the noradrenergic system modulates behavioral flexibility, controlling the switch between the exploration of many different actions and the exploitation of those specific actions that yield the greatest utility (Aston-Jones and Cohen, 2005a, b). This theory requires that noradrenergic projections have a great degree of target specificity. Support for this idea comes from recent findings suggesting that LC, rather than containing a homogeneous population of neurons as previously thought, is compartmentalized into distinct computational units (Chandler et al., 2014b) that each might have the capability to independently modulate select cortical areas (Mather et al., 2015; Chandler, 2016). In the present study we test the hypothesis that norepinephrine plays a causal role in action selection in a continuous motor space and that it exerts its effects by targeting a single motor cortical nucleus in the songbird vocal control circuit. Birdsong consists of precisely produced sequences of motor gestures that contain complex acoustic spectrotemporal structure on multiple timescales (Glaze and Troyer, 2006; Amador et al., 2013). Male zebra finches learn their song by adulthood, 
but even as adults they continue to alternate between highly precise "directed" song performed in the presence of a female and more variable, possibly exploratory, "undirected" song that is produced when singing alone (Sossinka and Boehner, 1980; Kao et al., 2005). Directed singing can be thought of as an exploitative behavior, where song is a precisely produced motor performance directed at the female (Tumer and Brainard, 2007; Andalman and Fee, 2009; Sober and Brainard, 2009; Ali et al., 2013). The more variable, undirected song has been suggested to promote active exploration of a motor space that facilitates learning of potentially new acoustic features (Tumer and Brainard, 2007; Sober and Brainard, 2009; Olveczky et al., 2011). The switch between the directed and undirected song types is mediated by a specialized basal ganglia circuit, known as the anterior forebrain pathway (AFP) (Figure 2a) (Farries, 2004; Reiner et al., 2004; Kao and Brainard, 2006; Farries and Perkel, 2008; Fee and Goldberg, 2011). Experimental inactivation of the AFP output nucleus LMAN causes the normally variable undirected song to become highly stereotyped and therefore resemble the acoustically precise directed song (Kao et al., 2005).

The locus coeruleus is highly conserved across vertebrates (Smeets and Gonzalez, 2000) and, in songbirds, it sends afferents throughout the "song control circuit" (Castelino and Schmidt, 2010). While NE transmission has been shown to modulate auditory response properties (Cardin and Schmidt, 2004; Castelino and Schmidt, 2010), its role in vocal production remains undefined (Hara et al., 2007). A key recipient of locus coeruleus input is the motor "cortical" area RA, a structure that is necessary for song production and serves as the major target of LMAN, the primary output nucleus of the AFP (Castelino and Schmidt, 2010). In vitro slice work provides 
84 indirect evidence that NE may influence vocal production because it can selectively suppress LMAN inputs onto RA without changing the strength of synaptic inputs from HVC, a premotor nucleus necessary for song production (Sizemore and Perkel, 2008). Noradrenergic release from LC terminals in RA therefore is well positioned to gate inputs from a basal ganglia circuit that is implicated in the generation of acoustic variability during undirected song (Kao et al., 2005; Kao and Brainard, 2006; Andalman and Fee, 2009).

Here we show evidence for direct influence of the noradrenergic system on acoustic variability through a combination of direct electrical stimulation of LC and reversible infusion of NE into RA in awake, freely moving birds.

\section{RESULTS}

\section{Quantification of differences between directed and undirected song variability}

\section{and singing rate.}

$$
\text { To capture the full extent that social context, or manipulation of the noradrenergic }
$$
system, might have on the spectro-temporal properties of song in the zebra finch, we developed a novel "Euclidean variability" measure that uses average Euclidean distance between syllables and respective time-warped templates in the spectral domain. Prior studies investigating changes in song variability between directed and undirected song relied primarily on changes in variability in the fundamental frequency of individual syllable portions (Kao and Brainard, 2006; Andalman and Fee, 2009), which limits 
analysis to a small subset of song elements that happen to be measurable in that feature space (i.e. have a clear fundamental frequency to begin with). Our more general measure was not restricted to any particular kind of song element, and we verified that our novel methodological approach both captured variance in fundamental frequency (figure 1c) and, as shown below, could replicate previous results by analyzing song in adult male zebra finches both under conditions of undirected song (male singing alone) and directed song (male singing in the presence of a female).

Songs were recorded from seven adult male zebra finches under both directed and undirected conditions, with motifs typically consisting of $3-9$ syllables (median=5). Using our more general spectral variability measurement, we confirmed that syllables produced during directed singing have significantly less spectral variability than those produced during undirected singing, with decreases in variability estimates for each syllable of $5.64 \pm 2.06 \%$ (figure $1 b$; hierarchical bootstrap t-test, $p<0.005$ ) with that direction of change holding in 6 of 7 birds. Variability differences appeared to hold across a wide variety of song syllables, many with complex structure that would not have been measurable with previous feature-based methods, indicating that contextdependent differences are generally spread across different song elements and not restricted to harmonic stack syllables with well-defined fundamental frequencies.

From this same dataset we also measured changes in song rhythmic (figure 1e) and tempo (figure $1 \mathrm{~g}$ ) variability during directed and undirected song using a statistical timing variability model previously shown to make principled definitions and estimates of these measures (Glaze \& Troyer, 2013, 2010). Specifically, rhythmic variability consists of rendition-to-rendition timing changes that are uncorrelated across a sequence of 
syllables and silent gaps between syllables in a motif, but nonetheless influence overall motif duration (unlike measurement error). In contrast, tempo variability measures the way in which all song elements in a given rendition become stretched or compressed in tandem. Interestingly, we found significant decreases in rhythmic variability (figure 1f) in the presence of a female with changes in this measure on a syllable-by-syllable and gap-by-gap basis of $12.48 \pm 7.66 \%$ (hierarchical bootstrap t-test, $p<0.005$ ), with the direction of change holding in 6 of 7 birds. By contrast, tempo variability showed an

137 increase of $56.44 \pm 26.00 \%$ (hierarchical bootstrap t-test, $p<0.05$; figure $1 \mathrm{~h}$ ), with that

138 direction of change persisting in 5 of 7 birds. As shown in previous studies (Sossinka and Boehner, 1980; Glaze and Troyer, 2006), there was a trend towards duration decreasing (tempo increasing) across time intervals in the presence of a female, with an average change of $0.4 \pm 0.4 \%$ that was consistent in 5 of 7 birds although it failed to

142 reach significance (hierarchical bootstrap t-test, $p=0.13$ ). female presence on song rate, with the presence of a female increasing the rate of vocal sequence production by an average of $1.372 \pm 0.63$ songs/minute (hierarchical

146 bootstrap t-test, $p=0.009$ ), with the direction of change holding in 5 of 7 birds (figure 147 1a). 
To examine the influence of the noradrenergic system on song production and variability parameters, we surgically implanted stimulating wires in LC (figure 2b) and quantified song features in the presence and absence of LC stimulation ( $N=4$ birds). Specifically, over a period of many days (3 - 12 days), we compared songs produced under non-stimulated control conditions with songs produced during 1-Hz tonic

157 stimulation of LC. Because we specifically were interested in whether an increase in noradrenergic tone caused by stimulation of LC would decrease the variability observed

159 during undirected song, all of the recordings in this first set of experiments were performed on males singing undirected song in the absence of females. Experiments consisted of periods of LC stimulation (1-2 hours) interleaved with periods of nonstimulation of roughly the same duration. Typical daily sessions consisted of 4-6 interleaved blocks, the order of which was alternated every other day (Figure 3a). Increases in noradrenergic tone are associated with motivation and an augmentation in behavioral drive. We therefore first tested the hypothesis that

166 activation of noradrenergic system would increase song rate. Consistent with this 167 hypothesis, stimulation of LC caused a significant increase in rate of undirected singing 168 in all 4 of the implanted birds. LC stimulation caused a mean increase in singing of 2.30 \pm 0.65 songs/minute (figure $3 b$; hierarchical bootstrap t-test, $p<0.0001$ ). To determine the effect of LC stimulation on syllable variability, we used our

171 novel "Euclidean variability" technique to quantify changes in spectral and temporal

172 variability across all song syllables. Locus coeruleus stimulation caused profound 173 changes in spectral variability, with stimulation during undirected singing decreasing 
spectral variability in all 4 birds by $4.25 \pm 0.74 \%$ (figure 3c; hierarchical bootstrap t-test, $\mathrm{p}<0.0001)$.

Given the observed changes on various aspects of timing variability between directed and undirected song, we also were interested in addressing whether similar changes in timing variability would be observed during LC stimulation of undirected song. Indeed, compared to unstimulated song, LC stimulation caused a decrease in rhythmic variability across time intervals by $9.41 \pm 3.08 \%$, with the direction of change persisting across all 4 birds (figure $3 d$; hierarchical bootstrap t-test, $p<0.005$ ). LC stimulation also indicated a trend of increased tempo variability by $95.57 \pm 35.7 \%$, with the direction of change holding in 3 of 4 birds (figure $3 e$; hierarchical bootstrap t-test, $p<0.05)$. Finally, LC stimulation also caused a modest but inconsistent increase in average tempo, with durations decreasing by $0.4 \pm 0.2 \%(p=0.178)$.

Thus, the directions of change effected by LC stimulation for singing rate and all of the spectral and temporal variability measurements were consistent with the directions of change observed by introducing a female (undirected to directed song) (Table 1).

\section{Targeted increases of norepinephrine in RA decrease spectral and rhythmic} variability of undirected song without increasing song rate 
197 motor system. To test the hypothesis that norepinephrine has a direct effect on motor performance, we used a microdialysis probe to infuse norepinephrine (NE) directly into RA, a cortical motor nucleus that projects directly to brainstem vocal-respiratory centers and serves as the final common output of the forebrain song control circuit (figure 4a). Based on prior in vitro studies in brains slices (Solis and Perkel, 2006; Sizemore and Perkel, 2008), we hypothesized that infusion of NE would inhibit inputs from LMAN onto RA in a presynaptic fashion and thereby selectively reduce the acoustic variability imposed by the anterior forebrain pathway.

A total of 8 birds were implanted with custom microdialysis probes targeted to the dorsal surface of RA. Care was taken not to place the probe directly into RA to avoid potential damage to RA (figure 4b). Birds implanted with microdialysis probes were infused on alternate days with either saline (control) or norepinephrine (NE) for periods ranging from 2 to 4 hours. Within each day, recording blocks were alternated between directed and undirected song. Because the current experiments were aimed at the hypothesis that elevations of NE in RA cause a decrease in song variability, songs were analyzed only under conditions of undirected song.

216 bootstrap t-test, $\mathrm{p}<0.0001)$. NE infusion into RA also decreased rhythmic variability in 7

217 of 8 birds by an average $17.45 \pm 7.07 \%$ (figure $5 d$; hierarchical bootstrap t-test, $p<0.01$ ). Interestingly, in contrast to the effects observed following LC stimulation, 
$5 e$; increase of $37.66 \pm 37.18 \%$, with the direction of change holding in 5 of 8 birds, hierarchical bootstrap t-test, $p=0.152)$ or in average tempo $(1.12 \pm 0.5 \%$; hierarchical bootstrap t-test, $p=0.067$ ). Similarly, norepinephrine infusion into RA did not affect song rate $(0.308 \pm 0.262$ more songs per minute compared with saline; figure $5 a$; hierarchical bootstrap t-test, $p=0.121$ ).

Taken together, these findings suggest that elevated levels of NE in RA only produce a subset of the effects observed following LC stimulation. While RA might be the target for several of the effects of norepinephrine (spectral and rhythmic variability), other target areas likely mediate effects such as song rate and tempo variability.

\section{Targeted infusion of RA with the NE receptor antagonist phentolamine increases} spectral and rhythmic variability of directed song.

\section{Data obtained from LC stimulation and NE infusion into RA are consistent with a} model in which the noradrenergic system gates the introduction of variability by the basal ganglia circuit into the motor system. We decided therefore to test the hypothesis that infusion of the non-selective alpha-adrenergic receptor antagonist phentolamine (PHE) during female-directed song, when NE should be elevated in RA, prevents NEmediated suppression of LMAN input onto RA and thereby increases spectral variability.

We infused PHE directly into RA in four birds and recorded song both in the absence and presence of a female. Birds were infused with saline on alternate days (figure 6a). Because the current experiments were aimed at the hypothesis that elevations of PHE in RA might increase song variability, songs were analyzed only 
243 under conditions when males were singing directed song in the presence of a female.

244 Song characteristics produced in the presence of PHE were compared directly to those

245 produced during saline infusion. PHE infusion increased spectral variability of directed

246 song in 3 of 4 birds, with an average increase of $8.22 \pm 3.19 \%$ (figure $6 c$; hierarchical

247 bootstrap t-test, $p<0.05)$. PHE infusion also increased rhythmic variability in 4 of 4 birds,

248 with an average increase of $12.38 \pm 5.71 \%$ (figure $6 \mathrm{~d}$; hierarchical bootstrap t-test,

$249 \mathrm{p}<0.05)$. Similar to the lack of effect of NE on tempo and tempo variability, PHE did not

250 yield a consistent effects on tempo variability (figure 6e) or mean tempo although there

251 was an insignificant trend toward decreasing tempo variability by $12.6 \pm 12.29 \%$ (trend in

2523 of 4 birds, hierarchical bootstrap t-test, $p=0.115$ ) and increasing average tempo by

$2530.6 \pm 0.8$ (direction of change in 2 of 2 birds, $p=0.205$ ). Also consistent with RA not

254 playing a significant role in song rate, PHE infusion did not affect song production rate

255 (1.065 $\pm 1.241 \%$ in 2 of 4 birds; hierarchical bootstrap t-test, $p=0.084$; figure $6 b)$.

257 inputs onto RA by administration of the receptor antagonist PHE causes an increase in spectral and rhythmic variability of directed song.

\section{DISCUSSION}

We investigated the influence of the noradrenergic system on the production of a

262 learned and ethologically relevant vocal behavior in male zebra finches. Direct

263 stimulation of the locus coeruleus in males singing alone (undirected song)

264 recapitulated all measured features of female-present songs (directed song). These

265 included (1) an increase in the frequency of produced songs, (2) greater spectral 
266 precision on fast timescales and (3) greater rhythmic precision on slower timescales.

267 Interestingly, direct infusion of NE into RA, a motor nucleus in the song system that is

268 analogous with primary motor cortex in mammals (Dugas-Ford et al., 2012), during undirected song resulted in greater spectral and rhythmic precision but did not increase song production or changes in tempo variability. Conversely, infusion of the non-

271 selective adrenergic alpha-receptor antagonist (PHE) into RA during directed song

272 singing resulted in decreased spectral and rhythmic precision without any statistically

273 significant influence on song production frequency or tempo variability. The findings are 274 summarized in Table 1.

The behavioral differences observed between the LC stimulation and direct, pharmacological manipulation in RA imply that song production rate and tempo variability is not mediated by noradrenergic modulation of RA and therefore likely is caused by direct or indirect effects of norepinephrine on other areas of the song control system. Possible targets for these additional effects on song might include the medial preoptic area, a midbrain nucleus that receives strong projections from LC, and which is known to project directly to the song system (Riters and Alger, 2004) and influence the motivation to sing (Riters and Ball, 1999; Riters et al., 2004). Our observation that a 283 single brain structure (nucleus RA) is responsible for changes in rhythmic and spectral variability of song suggests that NE can have direct effects on the motor system that are

285 distinct from a more generalized effect on arousal level and therefore provide support 286 for the idea that LC projections contain a degree of anatomical specificity that allow 287 them to differentially influence distinct cortical regions (Chandler et al., 2014a; Chandler, 2016). 


\section{Implications for models of motor variability in the song system}

The specificity of pharmacological effects suggests that increases in

norepinephrine in RA are capable of generating a degree of behavioral precision that is

inactivation of LMAN, the output nucleus of the basal ganglia circuit onto RA, or

the normally variable undirected song (Kao et al., 2005; Kao and Brainard, 2006; 
carry more variability than previously appreciated and that this variability is normally suppressed by elevated levels of NE in RA during female directed song. Alternatively, it is possible that elevated levels of NE during directed song might influence song variability by acting directly within RA. Given that alpha-2 NE receptor manipulation can change RA neuron excitability of RA in vitro (Solis and Perkel, 2006), it is possible that addition of PHE to RA prevents the stabilizing effects of NE on the RA network in a way that results in increased spectral and rhythmic variability.

Although this study has identified RA as a major target for NE effects on song variability, it is likely that norepinephrine can also influence the generation of motor variability at other loci given that $\mathrm{NE}$, perhaps in conjunction with dopamine (Leblois et al., 2010; Leblois and Perkel, 2012), acts directly on the basal ganglia (Area X) (Castelino and Ball, 2005) to reduce the generation of neural variability in pallidal neurons (Woolley et al., 2014).

\section{Implications for models of song timing and neural synchronization}

Single-unit recordings in HVC show that RA-projecting neurons each produce a single burst of action potentials that is precisely time-locked to distinct epochs in the song (Hahnloser et al., 2002; Lynch et al., 2016) with correlational data suggesting that these bursts control the timing in RA song premotor output (Fee et al., 2004). Because cooling of HVC, but not RA, slows overall song tempo (Long and Fee, 2008) it has been suggested that HVC controls much of song timing (Fiete et al., 2007; Long and Fee, 2008; Long et al., 2010). The observed effects of norepinephrine manipulation in RA on rhythmic variability of song are inconsistent with the simplest interpretation of these 
335 models and suggest that song timing control might be implemented in a more

336 distributed manner across the song system (Ashmore et al., 2005; Hamaguchi et al.,

337 2016; Schmidt and Goller, 2016): while HVC may influence RA timing, RA timing may

338 also influence the timing of spikes in HVC and elsewhere. Such an influence could be

339 direct, for example mediated by unilateral projections to HVC from the dorsal region of

RA (dRA) (Roberts et al. 2008) or indirect, as through recurrent bilateral inputs from the

341 RA-PAm-UVa-HVC pathway (Ashmore et al., 2005; Hamaguchi et al., 2016).

342 Interestingly, our findings leave open an interesting question as to why cooling RA does

343 not have any apparent influence on song given that NE and PHE infusion cause

344 changes in song timing. Perhaps cooling has a differential influence on the gain of

345 bursting activity in neurons in the dRA that preempts influence on spike timing in HVC.

346 In contrast, pharmacological manipulations of NE within RA might keep the gain

347 relatively intact while perturbing the statistical burst properties of RA neurons, which

348 could in turn propagate through HVC and the rest of the song system to modify song

349 timing.

350

Implications for the role of noradrenergic system in other systems

The noradrenergic system has been proposed to facilitate behavioral

353 optimization (Aston-Jones and Cohen, 2005a, b) as well as explore-exploit motor

354 learning. Under this theory, tonic increases in LC spiking and the associated increases

355 in norepinephrine enhance "distractibility" and promote exploration over a wide set of

356 possible salient stimuli or behaviors. In contrast, phasic LC spiking, and as a

357 consequence the more moderate increase in released NE, promote more focused task 
engagement and exploitation of actions previously learned as optimal for reward maximization. To date, this theory has been tested primarily in a discrete action space where optimal behavior is defined as a decision among a discrete set of options, such as in foraging tasks in which the subject must choose, within a given trial, among one of several options with uncertain reward value (Kalwani et al., 2014; Bouret and Richmond, 2015). In the zebra finch, we tested the role of NE in song production, which provides an interesting example of behavioral optimization. Here the optimal behavior is not the choice of a specific action but rather the choice of temporal and spectral motor commands in a sequenced, hierarchically organized composition of actions (Glaze and Troyer, 2006) that are produced in a continuous feature space (Tchernichovski et al., 2001). It is thus unclear what the analogue to phasic spiking would be in this context. In the current study, we manipulated NE levels either by direct infusion in RA or by imposing tonic $1 \mathrm{~Hz}$ stimulation in LC and therefore could not direct address phasic vs. tonic changes given that our manipulations caused sustained increases in NE levels. In future experiments it will be important to manipulate NE levels in a more phasic fashion as well as record from single units from LC during song production to gain greater insight into how the LC network promotes exploitation of learned behavioral sequences. More generally, the influence of NE on signal-to-noise ratios in individual neurons shown in songbirds (Solis and Perkel, 2006; Sizemore and Perkel, 2008) and mammals (Berridge and Waterhouse, 2003) suggest that while the noradrenergic system appears to have a very diverse set of influences across the central nervous system, the common principle may simply change the relative gain of influence of neural signals linked with the greatest salience or utility (Aston-Jones and Cohen, 2005b; Mather et al., 2015). 


\section{MATERIALS AND METHODS}

Subjects: Male and female zebra finches (Taeniopygia guttata) ranging from 120 to 250 days were used in this study. Animals were housed in same sex cages until the experiment commenced. Test males with either stimulating electrode or dialysis probe implants were housed alone in sound proof chambers. All the birds were housed on $14 \mathrm{~h}$ Light: 10h Dark and given food and water ad libitum.

LC stimulation: All implantation surgeries were performed on birds anesthetized with a mixture of ketamine (40mg/kg; Phoenix Pharmaceuticals, Belmont, CA) and xylazine (8 $\mathrm{mg} / \mathrm{kg}$; Phoenix Pharmaceuticals, Belmont, CA). A total of 17 male zebra finches were implanted with stereotrodes (25 $\mu$ m diameter nichrome wire). Although full length experiments were performed on most of the birds, several birds either died or lost their heads caps before we could perform electrolytic lesions to confirm electrode location. Of the remaining birds where we placed electrolytic lesions (60 $\mu \mathrm{A}$ for 10 seconds), we

397 were able to confirm that electrodes were placed in both the left and right LC in 4 birds 398 (Fig 2b). Electrode location was assessed visually in fresh unstained tissue with the criterion that the center of the lesion site be within the anatomical confines of the LC.

400 Implant placement was guided by a combination of stereotaxic coordinates and 401 electrophysiological landmarks. Implanted birds were tethered to a mercury commutator 402 that was connected to an A-M systems stimulator (Model 1800). Because the goal of these experiments was to test the effect of LC stimulation on undirected song, 
404 recordings were always made from male birds placed in a cage without a female. A typical experimental day consisted of LC stimulation periods ranging from 1 to 2 hours

406 that were interleaved with periods of non-stimulation of roughly the same duration for 407 approximately 6 hours each day. Experiments were designed so that the order of stimulation and non-stimulation periods was reversed on each experimental day (Figure 3a). Stimulation parameters consisted of tonic $1 \mathrm{~Hz}, 150 \mu \mathrm{A}$ bilateral, biphasic pulses of $400 \mu \mathrm{sec}$ duration. Such stimulation rates are consistent with median firing rates

411 observed in LC of awake behaving rodents (Fazlali et al., 2016). Each of the implanted 412 birds was subjected to this pattern of LC stimulation for 3 to 12 days.

Reverse microdialysis: A total of nine birds received microdialysis probe implants in each RA that were placed based on a combination of electrophysiological

416 characteristics and stereotaxic coordinates. Probes were aimed to the dorsal edge of

417 RA to minimize placing the cannula directly into RA and damaging the structure (figure 418 4b). Unlike injections, dialysis probes allow drugs to diffuse out of the cannula without adding any volume to the targeted area. Probes were manufactured according to

420 (Olveczky et al., 2011) using Spectra/Por ${ }^{\circledR}$ in vivo microdialysis hollow fibers (Spectrum

421 Labs, Ranchos Dominguez, CA) attached to polyimide tubing to make probes that had a

422 final overall diameter of approximately $250 \mu \mathrm{m}$. The dialysis membrane had a $13 \mathrm{kD}$ 423 cutoff which was sufficient to allow for diffusion of NE and phentolamine (PHE) into RA.

424 Probes placed in the left and right RA were connected to each other in series and drugs 425 were infused through FEP tubing (CMA/Microdialysis, Holliston, MA) that was 426 connected to the probes using a syringe pump (WPI, Sarasota, FL). Drugs and saline 
427 were infused through the probes at 2 to $4 \mathrm{ml} /$ hour. Probe placement in RA was verified by passing Fast Green dye or fluorescently tagged muscimol (BODIPY TMR-X muscimol conjugate, ThermoFisher Scientific) through the probe at the end of each experiment for approximately 30 minutes. Dye spread around the probe tip was combined with histological processing to verify the cannula tip was placed on the dorsal edge of RA. Norepinephrine (NE; Sigma-Aldrich) and the nonselective alpha-adrenergic receptor antagonist phentolamine (PHE; Sigma-Aldrich) were dissolved in physiological saline to a final concentration of $15 \mathrm{mM}$ for NE and PHE. Each testing day was divided up into 2 hours of singing in one context (e.g. female present) followed by 2 hours of singing in the other context (e.g. female absent). We recorded between 2 to 4 sessions 437 (of 2 hours each) per day, and alternated the order of social context (i.e. the presence or absence of a female) across consecutive days. Only one condition (drug or saline) was used on any given day, and this was alternated across consecutive days (Figures $5 a$ and $6 a)$. Overall duration of the experiments lasted 4 to 15 days.

Song recording and selection: Songs were digitized at $44.1 \mathrm{kHz}$ and collected as wav files using Song Analysis Pro (SAP) (Tchernichovski et al., 2000). Files were automatically screened in SAP for those most likely to contain song. The resulting wav file data were then analyzed using custom software written in Matlab (Mathworks,

446 Natick, MA). As described earlier, experimental conditions consisted of males housed 447 either in isolation or in the presence of a female. We defined undirected songs as those 448 songs produced when the male was singing by himself in the absence of a female. 
450 those songs produced by the male during the first 10 minutes after he was exposed to a

451 female. Songs produced after the first 10 minutes often contain a mixture of directed

452 and undirected song and therefore were not further analyzed in our studies because of

453 the ambiguity of defining the songs as being directed or undirected.

454

455 Song Analysis: The songs of each bird in each experimental condition were analyzed by

456 (1) using a fully automated custom-written user-trained pattern matching algorithm that

457 identifies song syllables across the entire data set and quantifies the most common

458 sequence of identified song syllables, (2) quantifying song characteristics such as

459 singing rates and the spectral and tempo variability of each syllable for each bird in 460 each experimental condition, and (3) computing statistics using a bootstrap procedure.

461 Each of these steps are described in more detail below:

1. Song syllable and motif identification: Each wav file was divided into sound clips using threshold crossings in the log-power of the signal. We then selected a random sample of 500-1000 clips from the resulting set (across all wav files). Individual sound

467 clips were transformed into spectrograms with a 512-point window slid forward in 256-

468 point steps and filtered between 500 and 9,000 Hz. Using a custom written GUI in

469 Matlab, each clip spectrogram was then manually classified as a particular song syllable 470 (e.g. syllable "a", syllable "b", etc.). Manual classification was based on a combination of 471 visual inspection, syllable playback, and statistics computed in the GUI that includes 
472 average fundamental frequency, Wiener entropy and Euclidean distance to other syllables in the sample.

The resulting "training set" was then used to automatically identify instances of each song syllable across the entire wav file set specific to each bird and experimental condition. Spectrograms for each syllable were reduced to 5 dimensions along the

477 frequency axis using Principal Components Analysis (PCA) to construct a basis vector 478 for each syllable. This information was then used to concatenate vectors for sound clip 479 spectrograms into a single matrix and associated with the 5 largest eigenvalues of the covariance matrix. Each clip was then projected onto the new basis to yield a $5 \times \mathrm{N}$

481 matrix, where $\mathrm{N}$ is the number of time points in the original clip spectrogram. Each wav 482 file across the entire data set was then treated with the same sequence of transformations as the sound clips, i.e. filtered between 500 and $9000 \mathrm{~Hz}$, transformed 484 into spectrograms and reduced to 5 dimensions along the frequency axis using the same principal components extracted from the training set. A sliding cross-correlation was then computed between each reduced clip and the reduced wav file, and a custom "sliding" k-nearest neighbors algorithm (Bishop, 2006) was used to identify instances of each syllable class. Specifically, for each time-point in the wav file, the 11 highest crosscorrelation scores were collected along with associated clip classes; a class (or "match") was then attached to a given time-point if at least half of the highest scores were associated with that class. In cases where two of the matches overlapped, the one with 492 the highest average score was chosen. 
495 picked the sequence with at least 2 syllables that was most common. Syllables were

496 considered adjacent in the same sequence if the silent gap between them was <200

497 msec of average duration. The resulting data set consisted of an average of 200 motif

498 renditions per bird per condition (range 59-484) and a median 5 syllables per motif

499 (range 3-9).

500

501

2. Quantifying song characteristics:

502

503

Singing rate analysis: To probe the frequency of singing per unit time we used an

automated algorithm that searched for at least two classified song syllables in sequence

505

(i.e. separated by $<200 \mathrm{msec}$ in average silent gap duration) and calculated the

506

frequency of occurrence per total time of song recording for that bird.

507

508

Syllable spectral analysis: Each unique syllable's rendition-to-rendition variability was

509

analyzed within the most common motif sequence for that bird. First, each syllable's

510

rendition was normalized by the total amount of power in the acoustic signal and

511 mapped to a time-base common to all renditions of that syllable using dynamic time-

512 warping (Rabiner et al., 1989). Specifically, syllable spectrograms were aligned and

513 averaged to yield a single template to which all renditions were mapped. Second, the

514 resulting mapped spectrograms were averaged and the process was repeated, resulting

515 in a "mean" syllable that had greater fidelity than the original. Third, we then calculated

516 the "spectro-temporal deviation" of each syllable rendition as the Euclidean distance

517 between rendition $j$ of syllable $k$ and the mean of syllable $k$ as: 


$$
d_{k j}=\sqrt{\frac{1}{N M} \sum_{n m}\left(X_{k j n m}-\bar{X}_{k n m}\right)^{2}}
$$

519 Where $N$ and $M$ are the number of time and frequency bins, $n$ and $m$ index time and 520 frequency, $X$ is the spectrogram of a syllable rendition, and $\bar{X}$ is the averaged syllable

521 template described above. Fourth, we then computed total syllable-specific "spectro-

522 temporal variability" (within a given experimental condition) as:

$$
v_{k}=\sqrt{\frac{1}{L} \sum_{j} d_{k j}^{2}}
$$

524 Where $L$ is the total number of renditions for that syllable.

526 The values of $d_{k j}$ and $v_{k}$ can be thought of simply as broad measures of how "different" a 527 syllable sounds from its average rendition, encompassing variability in the fundamental 528 frequency of a vocalization with well-defined pitch, as well as variability in more complex 529 sound features such as those found in amplitude-modulated notes and sweeps.

531 have focused on the fundamental frequency (FF) of song elements that have a well-

532 defined pitch (e.g. "harmonic stacks"). The more general measure of spectral variability

533 we use here makes fewer assumptions about the nature of the signal. In a subset of syllables with a well-defined fundamental frequency we verified that the measure, which

535 is represented in arbitrary units (A.U.), was correlated with estimates of FF (e.g. figure $5361 \mathrm{c}, \mathrm{d})$. 
538 Timing variability analysis: To measure precise differences in timing variability we re-

539 calculated song spectrograms using 256-point windows slid forward in 128-point steps

540 and calculated for each song syllable a template of the time-derivative using methods

541 described previously (Glaze and Troyer, 2007, 2013). We then applied a dynamic time-

542 warping algorithm (Rabiner et al., 1989; Glaze and Troyer, 2006, 2007) to measure

543 syllable onset and offset times, yielding a sequence of syllable onset and offset times

544 for each bird and associated motif, defining "time intervals" as the duration from either

545 syllable onset to offset (i.e. syllable duration) or syllable offset to the onset of the next

546 (silent gap durations). Finally, we decomposed rendition-to-rendition timing variability

547 across the sequence into variations linked with global tempo modulations and variations

548 independent of both tempo of measurement error in onset and offset times using a

549 generative model described previously (Glaze and Troyer, 2012) (figure 1e,g).

550 Specifically, we wrote time interval $i$ in rendition $n$ as:

551

$$
x_{k n}=W_{k} z_{n}+\eta_{k n}+\left\{\begin{array}{cc}
-u_{k-1, n}+u_{k n} & 1<k<K \\
u_{1 n} & k=1 \\
-u_{k-1, n} & k=K
\end{array}\right.
$$

552 Where $x$ is the time interval, $z$ is the (0-mean, unit-variance) tempo for that rendition, $W$

553 is the relative contribution of interval $x$ to this shared tempo, $u$ is jitter in the onset/offset

554 time measurement that does not contribute to overall motif duration, $K$ is the total

555 number of time intervals in the motif, and $\eta$ is the timing variable independent of both

556 tempo and jitter, influencing overall song duration independently of the other intervals.

557 This last component may be thought of intuitively as "rhythmic variability" because it

558 significantly changes the proportional durations of each sequence element significantly 
559 more than the global component and cannot in principal be attributed to measurement error because it influences the timing of every subsequent element (Glaze, 2008; Glaze and Troyer, 2012). previous studies estimating these components, making estimation especially susceptible to sample error using maximum likelihood techniques. We thus used a modified version of an expectation-maximization (EM) algorithm previously developed to

566 make component estimates (Glaze and Troyer, 2012). The central difference here was

567 in the "maximization step". Here estimates at each iteration of the algorithm were based on maximizing the posterior probability of each parameter given the data and (1) a 0mean, unit-variance Gaussian prior probability distribution constraining estimates of W and (2) an exponential prior probability distribution constraining estimates of the total

571 variance in $\eta$ (i.e. rhythmic variability). Component estimates corroborated previous

572 findings from the maximum-likelihood based method that global timing changes were

573 indeed dominated by a shared positive correlation in trial-to-trial variability among all

574 time intervals, with $\sim 94 \%$ of tempo weights $(W)$ being positive, and roughly the same

575 amounts of variability in the tempo and rhythmic variability components (medians of

\section{Statistical analysis}

Analysis was focused in 5 key measurements described above: (1) rate of

580 singing, (2) rendition-to-rendition spectral variability in each syllable, (3) average

581 duration of each syllable and silent gap, (4) magnitude of tempo variability contributed 
by each syllable and gap, and (5) rhythmic variability contributed by each syllable and gap independently of the rest. Analysis was performed for each of these measures across different experimental conditions: (i) presence of a female, (ii) stimulation of LC (iii) infusion of NE into RA or (iv) infusion of PHE into RA.

We tested for the significance of each of these effects using a bootstrapping procedure (Davison and Hinkley, 1997) that accounted for random sampling of both individual birds and syllables rather than treating each syllable independently.

Specifically, for each hypothesis test we constructed 1000 bootstrapped samples of the mean difference in measurement across conditions by re-sampling individual birds and song renditions with replacement. A single bootstrapped mean was thus calculated as the average across a set of differences obtained by (1) randomly sampling a bird, (2) randomly sampling motif renditions for that bird, (3) computing song rate, syllable variability and timing variability over that sample, (4) repeating steps (1) and (3) until the total number of birds for the given experiment (e.g. LC stimulation) had been selected, and (5) calculating the mean of paired differences between conditions. We then calculated standard errors on mean differences as the standard deviation of the resulting distribution of differences. We then defined statistical significance with the percentage of all bootstrapped samples falling below/above 0 per each hypothesis, using a two-tailed $5 \%$ threshold (i.e. significant difference if $97.5 \%$ of samples either fall above or below 0 ). In our calculations of song rate, bootstrapped samples of differences in rate of song production were calculated by taking the total number of vocal sequences produced across the random bird sample and dividing by the total amount of song recording time in order to avoid the disproportionate influence of birds 
605 with relative small song recording time durations. Throughout, we refer to this as a

606 "hierarchical bootstrap test" and report p-values based on the percentage of

607 bootstrapped samples falling below/above 0 along with the mean and standard

608 deviation of the sample distribution (the latter yielding standard errors on the

609 differences). We report the consistency of effect differences across birds using median

610 parameter differences by bird where parameters were calculated across all samples for

611 each bird.

612

613 Conflict of Interest: None

614

615

616 Acknowledgements: We thank David Perkel and members of the Schmidt lab for

617 reading an earlier version of this manuscript. We also thank the three reviewers for

618 insightful comments that helped significantly improve the manuscript. We are also

619 indebted to Richard Hahnloser and Janie Ondracek for teaching us how to make the

620 microdialysis probes.

621 


\section{REFERENCES}

Ali F, Otchy TM, Pehlevan C, Fantana AL, Burak Y, Olveczky BP (2013) The basal ganglia is necessary for learning spectral, but not temporal, features of birdsong. Neuron 80:494-506.

Amador A, Perl YS, Mindlin GB, Margoliash D (2013) Elemental gesture dynamics are encoded by song premotor cortical neurons. Nature 495:59-64.

Andalman AS, Fee MS (2009) A basal ganglia-forebrain circuit in the songbird biases motor output to avoid vocal errors. Proc Natl Acad Sci U S A 106:12518-12523.

Appeltants D, Ball GF, Balthazart J (2001) The distribution of tyrosine hydroxylase in the canary brain: demonstration of a specific and sexually dimorphic catecholaminergic innervation of the telencephalic song control nulcei. Cell and tissue research 304:237-259.

Appeltants D, Ball GF, Balthazart J (2002) The origin of catecholaminergic inputs to the song control nucleus RA in canaries. Neuroreport 13:649-653.

Ashmore RC, Wild JM, Schmidt MF (2005) Brainstem and forebrain contributions to the generation of learned motor behaviors for song. The Journal of neuroscience : the official journal of the Society for Neuroscience 25:8543-8554.

Aston-Jones G, Cohen JD (2005a) An integrative theory of locus coeruleusnorepinephrine function: Adaptive gain and optimal performance. Annual Review of Neuroscience 28:403-450.

Aston-Jones G, Cohen JD (2005b) Adaptive gain and the role of the locus coeruleusnorepinephrine system in optimal performance. The Journal of comparative neurology 493:99-110.

Berridge CW, Waterhouse BD (2003) The locus coeruleus-noradrenergic system: modulation of behavioral state and state-dependent cognitive processes. Brain Research Reviews 42:33-84.

Bishop CM, ed (2006) Pattern Recognition and Machine Learning. Singapore: Springer Science+Business Media, LLC.

Bouret S, Richmond BJ (2015) Sensitivity of locus ceruleus neurons to reward value for goal-directed actions. J Neurosci 35:4005-4014.

Cardin JA, Schmidt MF (2004) Noradrenergic inputs mediate state dependence of auditory responses in the avian song system. The Journal of neuroscience : the official journal of the Society for Neuroscience 24:7745-7753.

Castelino CB, Ball GF (2005) A role for norepinephrine in the regulation of contextdependent ZENK expression in male zebra finches (Taeniopygia guttata). European Journal of Neuroscience 21:1962-1972.

Castelino CB, Schmidt MF (2010) What birdsong can teach us about the central noradrenergic system. Journal of chemical neuroanatomy 39:96-111.

Castelino CB, Diekamp B, Ball GF (2007) Noradrenergic projections to the song control nucleus area $X$ of the medial striatum in male zebra finches (Taeniopygia guttata). Journal of Comparative Neurology 502:544-562.

Chandler DJ (2016) Evidence for a specialized role of the locus coeruleus noradrenergic system in cortical circuitries and behavioral operations. Brain Res 1641:197-206. 
Chandler DJ, Waterhouse BD, Gao WJ (2014a) New perspectives on catecholaminergic regulation of executive circuits: evidence for independent modulation of prefrontal functions by midbrain dopaminergic and noradrenergic neurons. Front Neural Circuits 8:53.

Chandler DJ, Gao WJ, Waterhouse BD (2014b) Heterogeneous organization of the locus coeruleus projections to prefrontal and motor cortices. Proc Natl Acad Sci U S A 111:6816-6821.

Charlesworth JD, Tumer EC, Warren TL, Brainard MS (2011) Learning the microstructure of successful behavior. Nature neuroscience 14:373-380.

Davison AC, Hinkley DV (1997) Bootstrap Methods and their Applications: Cambridge University Press.

Dugas-Ford J, Rowell JJ, Ragsdale CW (2012) Cell-type homologies and the origins of the neocortex. P Natl Acad Sci USA 109:16974-16979.

Farries MA (2004) The avian song system in comparative perspective. Annals of the New York Academy of Sciences 1016:61-76.

Farries MA, Perkel DJ (2008) The songbird brain in comparative perspective. In: Neuroscience of Birdsong (Zeigler HP, Marler P, eds), pp 63 - 72. New York: Cambridge University Press.

Fazlali Z, Ranjbar-Slamloo Y, Adibi M, Arabzadeh E (2016) Correlation between Cortical State and Locus Coeruleus Activity: Implications for Sensory Coding in Rat Barrel Cortex. Front Neural Circuits 10:14.

Fee MS, Goldberg JH (2011) A hypothesis for basal ganglia-dependent reinforcement learning in the songbird. Neuroscience 198:152-170.

Fee MS, Kozhevnikov AA, Hahnloser RHR (2004) Neural mechanisms of vocal sequence generation in the songbird. Behavioral Neurobiology of Birdsong 1016:153-170.

Fiete IR, Fee MS, Seung HS (2007) Model of birdsong learning based on gradient estimation by dynamic perturbation of neural conductances. Journal of neurophysiology 98:2038-2057.

Glaze CM (2008) Temporal Structure in Zebra Finch Song: Implications for the Motor Code and Learning Process. In. College Park, MD: University of Maryland.

Glaze CM, Troyer TW (2006) Temporal structure in zebra finch song: Implications for motor coding. The Journal of neuroscience : the official journal of the Society for Neuroscience 26:991-1005.

Glaze CM, Troyer TW (2007) Behavioral measurements of a temporally precise motor code for birdsong. The Journal of neuroscience : the official journal of the Society for Neuroscience 27:7631-7639.

Glaze CM, Troyer TW (2012) A generative model for measuring latent timing structure in motor sequences. PLoS One 7:e37616.

Glaze CM, Troyer TW (2013) Development of temporal structure in zebra finch song. Journal of neurophysiology 109:1025-1035.

Hahnloser RHR, Kozhevnikov AA, Fee MS (2002) An ultra-sparse code underlies the generation of neural sequences in a songbird. Nature 419:65-70.

Hamaguchi K, Tanaka M, Mooney R (2016) A Distributed Recurrent Network Contributes to Temporally Precise Vocalizations. Neuron 91:680-693. 
Hara E, Kubikova L, Hessler NA, Jarvis ED (2007) Role of the midbrain dopaminergic system in modulation of vocal brain activation by social context. European Journal of Neuroscience 25:3406-3416.

Hasselmo ME, Linster C, Patil M, Ma D, Cekic M (1997) Noradrenergic suppression of synaptic transmission may influence cortical signal-to-noise ratio. Journal of neurophysiology 77:3326-3339.

Kalwani RM, Joshi S, Gold JI (2014) Phasic activation of individual neurons in the locus ceruleus/subceruleus complex of monkeys reflects rewarded decisions to go but not stop. J Neurosci 34:13656-13669.

Kao MH, Brainard MS (2006) Lesions of an avian basal ganglia circuit prevent contextdependent changes to song variability. Journal of neurophysiology 96:14411455.

Kao MH, Doupe AJ, Brainard MS (2005) Contributions of an avian basal gangliaforebrain circuit to real-time modulation of song. Nature 433:638-643.

Kao MH, Wright BD, Doupe AJ (2008) Neurons in a forebrain nucleus required for vocal plasticity rapidly switch between precise firing and variable bursting depending on social context. J Neurosci 28:13232-13247.

Kety S (1972) Brain catecholamines, affective states and memory. In: The Chemistry of Mood, Motivation and Memory (McGraugh JL, ed), pp 65-80. New York: Plenum Press.

Kojima S, Kao MH, Doupe AJ (2013) Task-related "cortical" bursting depends critically on basal ganglia input and is linked to vocal plasticity. Proc Natl Acad Sci U S A 110:4756-4761.

Leblois A, Perkel DJ (2012) Striatal dopamine modulates song spectral but not temporal features through D1 receptors. Eur J Neurosci 35:1771-1781.

Leblois A, Wendel BJ, Perkel DJ (2010) Striatal dopamine modulates basal ganglia output and regulates social context-dependent behavioral variability through D1 receptors. J Neurosci 30:5730-5743.

Long MA, Fee MS (2008) Using temperature to analyse temporal dynamics in the songbird motor pathway. Nature 456:189-194.

Long MA, Jin DZ, Fee MS (2010) Support for a synaptic chain model of neuronal sequence generation. Nature 468:394-399.

Lynch GF, Okubo TS, Hanuschkin A, Hahnloser RH, Fee MS (2016) Rhythmic Continuous-Time Coding in the Songbird Analog of Vocal Motor Cortex. Neuron 90:877-892.

Mather M, Clewett D, Sakaki M, Harley CW (2015) Norepinephrine ignites local hot spots of neuronal excitation: How arousal amplifies selectivity in perception and memory. The Behavioral and brain sciences:1-100.

Olveczky BP, Andalman AS, Fee MS (2005) Vocal experimentation in the juvenile songbird requires a basal ganglia circuit. Plos Biology 3:902-909.

Olveczky BP, Otchy TM, Goldberg JH, Aronov D, Fee MS (2011) Changes in the neural control of a complex motor sequence during learning. Journal of neurophysiology 106:386-397.

Rabiner LR, Wilpon JG, Soong FK (1989) High Performance Connected Digit Recognition Using Hidden Markov Models. IEEE International Conference on Acoustics, Speech, and Signal Processing 37:1214 - 1225. 
770

771

772

773

774

775

776

777

778

779

780

781

782

783

784

785

786

787

788

789

790

791

792

793

794

795

796
Reiner A, Perkel DJ, Mello CV, Jarvis ED (2004) Songbirds and the revised avian brain nomenclature. Ann NY Acad Sci 1016:77-108.

Riters LV, Ball GF (1999) Lesions to the medial preoptic area affect singing in the male European starling (Sturnus vulgaris). Horm Behav 36:276-286.

Riters LV, Alger SJ (2004) Neuroanatomical evidence for indirect connections between the medial preoptic nucleus and the song control system: possible neural substrates for sexually motivated song. Cell and tissue research 316:35-44.

Riters LV, Teague DP, Schroeder MB, Cummings SE (2004) Vocal production in different social contexts relates to variation in immediate early gene immunoreactivity within and outside of the song control system. Behav Brain Res 155:307-318.

Schmidt MF, Goller F (2016) Breathtaking Songs: Coordinating the Neural Circuits for Breathing and Singing. Physiology 31:442-451.

Sizemore M, Perkel DJ (2008) Noradrenergic and GABA(B) receptor activation differentially modulate inputs to the premotor nucleus RA in zebra finches. Journal of neurophysiology 100:8-18.

Smeets WJ, Gonzalez A (2000) Catecholamine systems in the brain of vertebrates: new perspectives through a comparative approach. Brain Res Brain Res Rev 33:308379.

Sober SJ, Brainard MS (2009) Adult birdsong is actively maintained by error correction. Nature neuroscience 12:927-931.

Solis MM, Perkel DJ (2006) Noradrenergic modulation of activity in a vocal control nucleus in vitro. Journal of neurophysiology 95:2265-2276.

Sossinka R, Boehner J (1980) Song types in the zebra finch Poephila guttata castanotis. Z Tierpsychol 53:123-132.

Stepanek L, Doupe AJ (2010) Activity in a cortical-basal ganglia circuit for song is required for social context-dependent vocal variability. Journal of neurophysiology 104:2474-2486.

Tchernichovski O, Mitra PP, Lints T, Nottebohm F (2001) Dynamics of the vocal imitation process: How a zebra finch learns its song. Science 291:2564-2569.

Tchernichovski O, Nottebohm F, Ho CE, Pesaran B, Mitra PP (2000) A procedure for an automated measurement of song similarity. Animal behaviour 59:1167-1176.

Tumer EC, Brainard MS (2007) Performance variability enables adaptive plasticity of 'crystallized' adult birdsong. Nature 450:1240-U1211.

Woolley SC, Doupe AJ (2008) Social context-induced song variation affects female behavior and gene expression. PLoS Biol 6:e62.

Woolley SC, Rajan R, Joshua M, Doupe AJ (2014) Emergence of context-dependent variability across a basal ganglia network. Neuron 82:208-223. 


\section{FIGURE LEGENDS}

798

799

800

801

802

803

804

805

806

807

808

809

810

811

812

813

814

815

816

817

818

819

\section{Figure 1. Context-dependence of the behavioral parameters extracted for} analysis. (A) Scatterplot of the average number of songs produced per minute of recording from each bird by context. Measures taken from the female-present context (directed song) fall along the vertical axis and those taken from alone-context (undirected song) fall along the horizontal axis. Each bird is indicated by different symbols or colors. (B) Scatterplot of the total amount of trial-to-trial spectral variability in each song syllable by context (34 syllables in 7 birds). Vertical axis is the femalepresent context and the horizontal axis male-alone context. Units are arbitrary and therefore indicated as A.U. (Arbitrary Units). Syllables from individual birds are represented by different symbols or colors $(C, D)$ : Validation of the novel analytical method used to compute the variability measures in (B) (see Methods for details). Segment of a song syllable from one bird with a stable and clearly defined fundamental frequency, rendering it amenable to the standard analysis of variability as in previous investigations into context-dependence of trial-to-trial spectral variability. (D) Scatterplot of spectral distance measured using the novel method on the vertical-axis vs. fundamental frequency deviations from the average along the horizontal axis for the same syllable segment indicated in (C). Data are plotted for 498 renditions of the same syllable. $(\mathrm{E}-\mathrm{H})$ Trial-to-trial timing variability model and context-dependent parameter estimates. (E) Schematic illustrating an example of rhythmic variability, in which trial-totrial deviations in the time intervals between identified song features (e.g. syllable onsets and offsets) are independent but significantly affect overall song duration. (F) Scatterplot of the total amount of trial-to-trial rhythmic variability in each song syllable by 
820

821

822

823

824

825

826

827

828

829

830

831

832

833

834

835

836

837

838

839

840

context. (G) Schematic illustrating an example of tempo variability, in which trial-to-trial deviations in the time intervals between identified song features are correlated, preserving the relative durations of the time intervals much more than rhythmic variability. $(\mathrm{H})$ Scatterplot of the total amount of trial-to-trial tempo variability in each song syllable by context, with axes as in (A, B, F). All birds used in these analyses were the same as those used for the infusion experiment (Figures 4, 5 and 6).

Figure 2. Locus Coeruleus projections to the song control system. We used stimulating electrodes placed bilaterally in the locus coeruleus (LC) to test the effect of tonic $1 \mathrm{~Hz}$ stimulation on spectral variability of undirected song. (A) Schematic illustration of the known projections of LC onto HVC (Appeltants et al., 2001), RA (Appeltants et al., 2002), and area $X$ (Castelino et al., 2007) in the song control system. (B) Coronal section of the midbrain showing successful bilateral placement of stimulating electrodes in LC. Individual electrode placement is illustrated by blue, green, yellow and red dots. Anatomical abbreviations: LMAN: lateral magnocellular nucleus of the anterior nidopallium; DLM: medial nucleus of the dorsolateral thalamus; RA: robust nucleus of the arcopallium ; HVC: used as proper name; Cb: cerebellum; LC: locus coeruleus; PB: parabrachial n.; FLM: Fasciculus longitudinalis medialis; LP: lateral pontine n. ; MP: medial pontine n.; SCv: ventral subcoeruleus ; TD: dorsal tegmental n.; DR: dorsal raphe. 
841 Figure 3. Stimulation of the Locus Coeruleus increases singing rate and

842 decreases the spectral and rhythmic variability of undirected song. (A) Timeline of

843 experimental paradigm (B) Scatterplot of the average number of songs produced per

844 minute of recording from each of the 4 birds by experimental condition. Measures taken

845 from the LC-stimulation condition fall along the vertical axis and those taken from the

846 no-stimulation along the horizontal axis. (C-E) Scatterplots of spectral variability (C),

847 rhythmic variability (D), and tempo variability (E) plotted for each song syllable (25

848 different syllables across the 4 birds), with axes as in (B). Syllables produced by each

849 bird are indicated by different symbols or colors.

Figure 4. Infusion of norepinephrine directly into nucleus RA. (A) Illustration of the song system and probe implant into nucleus RA used for the microdialysis technique described in Methods. (B) Histology slide verifying anatomical location of probe implant in one bird by passing of fluorescently tagged muscimol through the probe after the experiment. Probes were typically placed in the dorsal pat of RA to prevent damage to the structure. RA contour is shown by the white dotted lined and probe by the yellow

857 dotted line. Calibration bar $=500 \mu \mathrm{m}$. (C) Spectral variability scatterplot for a song syllable segment with a well-defined fundamental frequency as in Fig. 1C, with trial-bytrial spectral distance from the mean segment calculated using the novel method along the vertical axis and the more standard distance in fundamental frequency from the mean along the horizontal axis. Measurements during NE infusion are in green and

862 those during saline are in black. (D) Spectrogram of the syllable analyzed in (C) along with key segment for which variability measurements were extracted. (E, F) Histograms 
864 of fundamental frequency during infusion of saline $(E)$ and NE $(F)$, with measured standard deviations indicated to the right. Overall, the analysis demonstrates a robust decrease in variability during confirmed NE infusion into RA that can be measured either with the novel or standard method.

Figure 5. Direct infusion of norepinephrine into nucleus RA decreases spectroof $\operatorname{NE}(C, D, E)$ on the vertical axis and saline infusion condition on the $x$-axis. (B):

872 Number of songs produced per minute of recording, with each symbol representing 873 song rate for each of the 8 birds. (C) Spectral variability measurements using novel

874 method; (D) rhythmic variability and (E) tempo variability. The analysis suggests that norepinephrine infusion into nucleus RA significantly decreased spectral and rhythmic variability in males singing undirected song. adrenergic receptor antagonist phentolamine (PHE)) on the vertical axis and saline infusion condition on the x-axis. (B) Number of songs produced per minute of recording, with each symbol representing song rate for each of the 4 birds. Three of these birds were also used for the NE infusion experiments (C) Spectral variability measurements using novel method; (D) rhythmic variability and $(E)$ tempo variability. The analysis 
bioRxiv preprint doi: https://doi.org/10.1101/218479; this version posted November 13, 2017. The copyright holder for this preprint (which was not certified by peer review) is the author/funder, who has granted bioRxiv a license to display the preprint in perpetuity. It is made available under aCC-BY 4.0 International license.

886 suggests that phentolamine infusion increases both spectral and rhythmic variability of

887 female directed song.

888 


\begin{tabular}{|c|c|c|c|c|}
\hline & \multicolumn{3}{|c|}{ Relative to Undirected Song } & Relative to Directed Song \\
\hline & Direct & Undirect - LC Stim & Undirect - NE in RA & Direct - PHE in RA \\
\hline Spectral va riability & decrease (5.6\%) & decrease $(4.5 \%)$ & decrease $(4.74 \%)$ & increase $(8.2 \%)$ \\
\hline Rhythmic variability & decrease $(12 \%)$ & decrease $(9.41 \%)$ & decrease $(17 \%)$ & increase $(12.3 \%)$ \\
\hline Tempo variability & increase (56\%) & increase (95\%) & no change & no change \\
\hline Tempo & no change & no change & no change & no change \\
\hline Song rate & increase & increase & no change & no change \\
\hline
\end{tabular}

892 Title: Summary of effects of NE manipulation on Song Features

894 Legend: LC stimulation of undirected song cause similar changes to song

895 characteristics as the transition from undirected to directed song. In contrast, infusion of

896 NE directly into RA only causes changes in spectral and rhythmic variability. The

897 receptor antagonist PHE causes the exact opposite effect of NE when infused in RA

898 while birds are singing directed song. 
bioRxiv preprint doi: https://doi.org/10.1101/218479; this version posted November 13, 2017. The copyright holder for this preprint (which was not certified by peer review) is the author/funder, who has granted bioRxiv a license to display the preprint in perpetuity. It is made available under aCC-BY 4.0 International license.

\section{FIGURE 1}

A Singing Frequency (songs/minute)

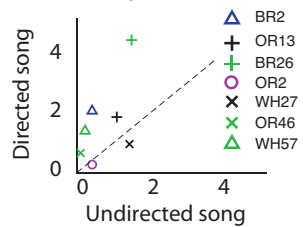

B

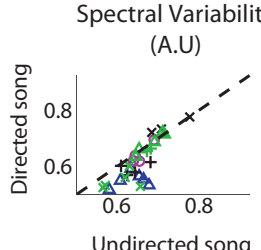

C
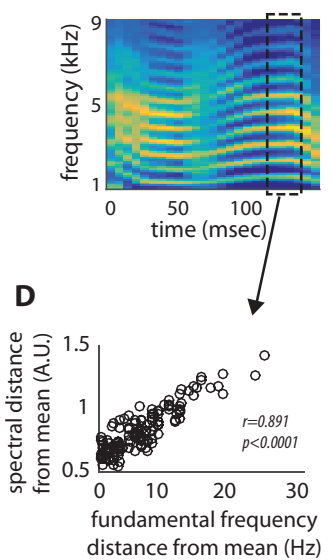

E

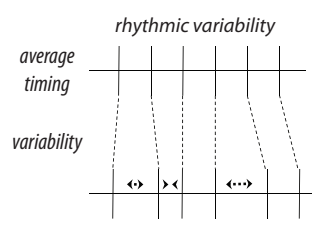

F Rhythmic Variability

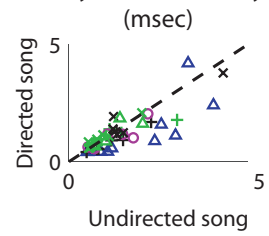

G

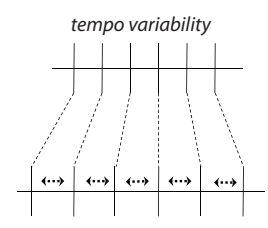

H Tempo Variability

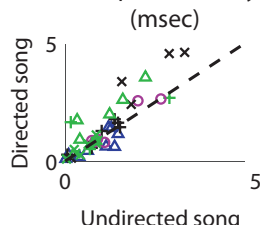

Glaze et al. FIGURE 1 
bioRxiv preprint doi: https://doi.org/10.1101/218479; this version posted November 13, 2017. The copyright holder for this preprint (which was not certified by peer review) is the author/funder, who has granted bioRxiv a license to display the preprint in perpetuity. It is made available under aCC-BY 4.0 International license.

\section{FIGURE 2}

908

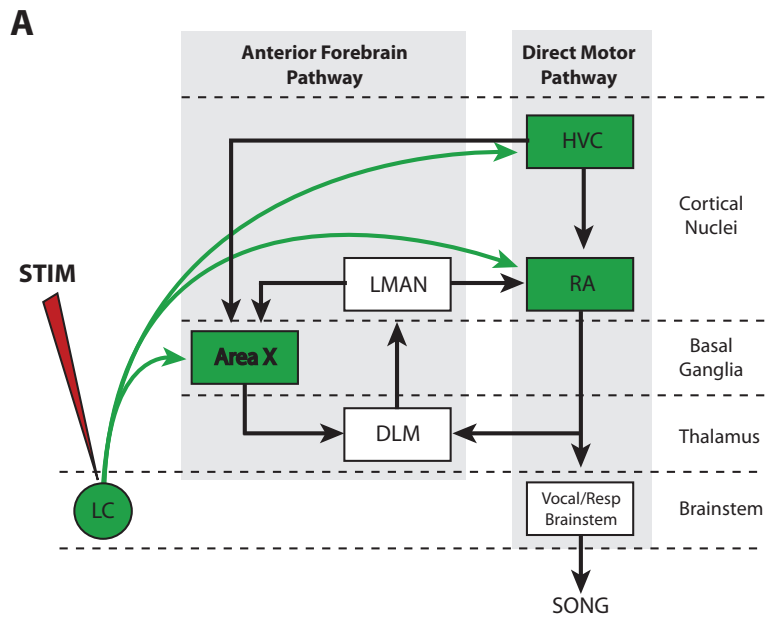

A
B

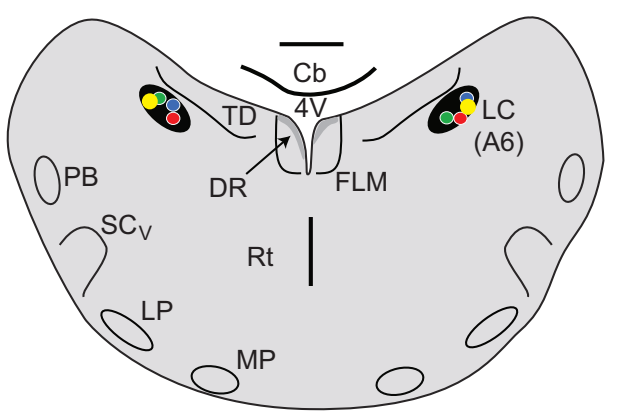

909

910

911

912

913 


\section{FIGURE 3}

915

A

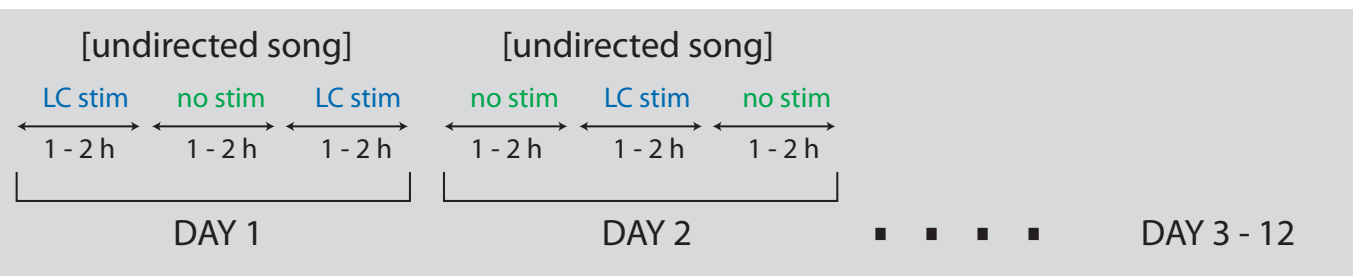

B Singing Frequency (songs/minute)

D Rhythmic Variability (msec)

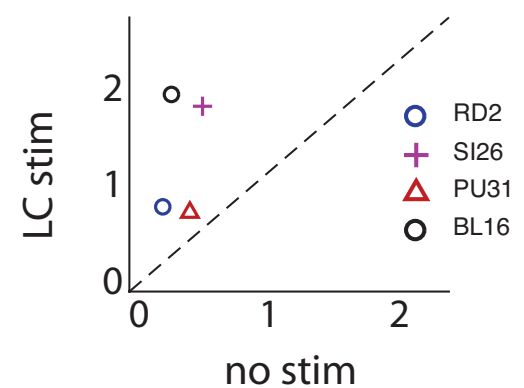

C Spectral Variability (A. U.)

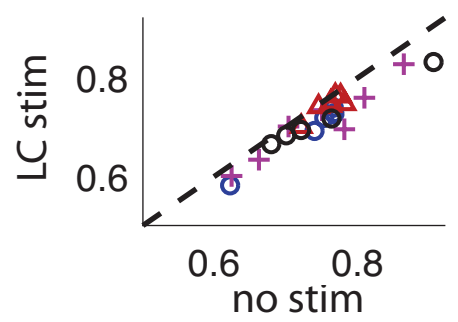

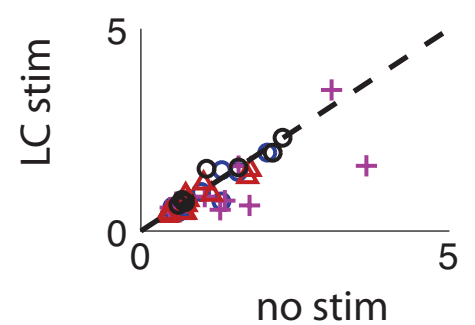

E Tempo Variability (msec)

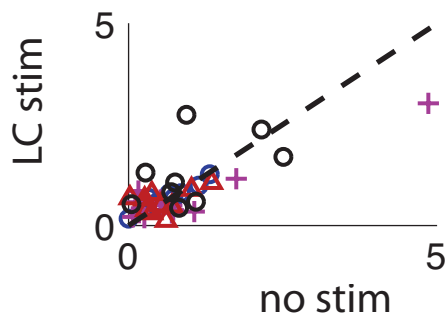




\section{FIGURE 4}

923
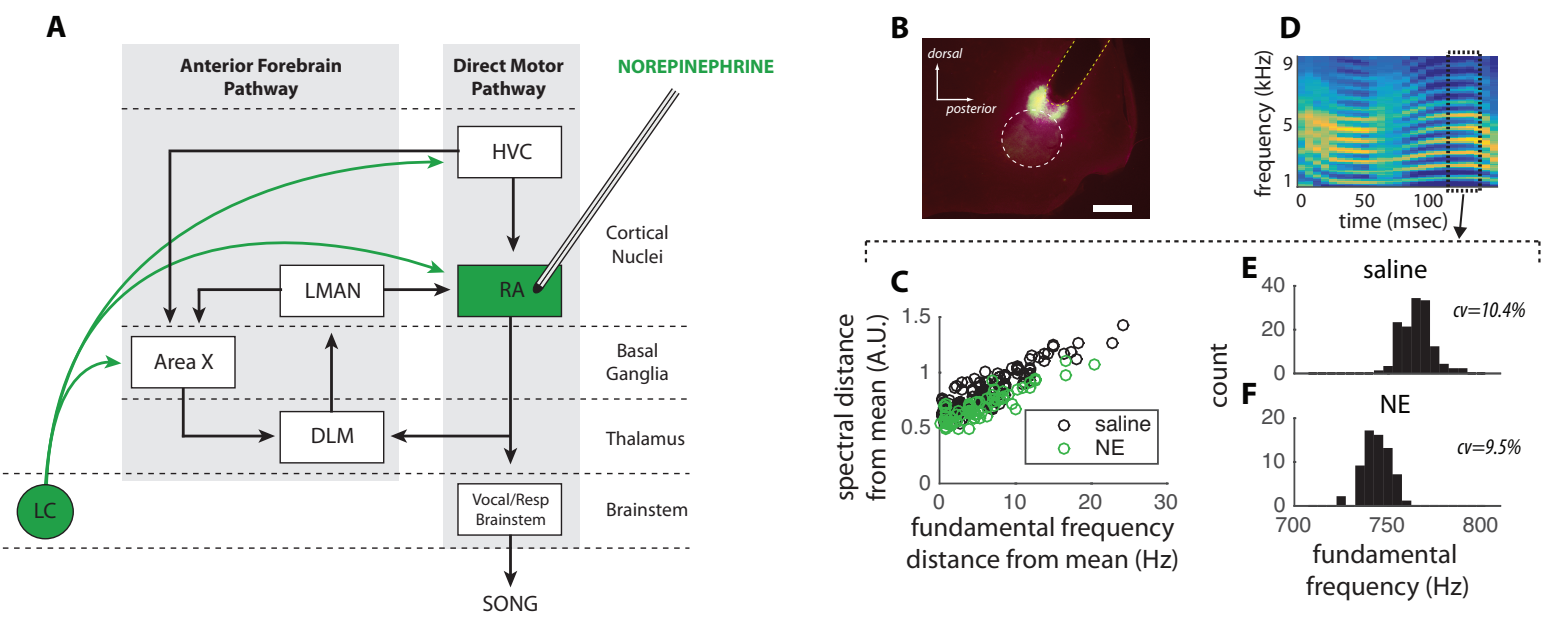

925

926

927

928

929

930

931

932

933

934

935

936

937

938

939 
bioRxiv preprint doi: https://doi.org/10.1101/218479; this version posted November 13,2017 . The copyright holder for this preprint (which was not certified by peer review) is the author/funder, who has granted bioRxiv a license to display the preprint in perpetuity. It is made available under aCC-BY 4.0 International license.

941

A
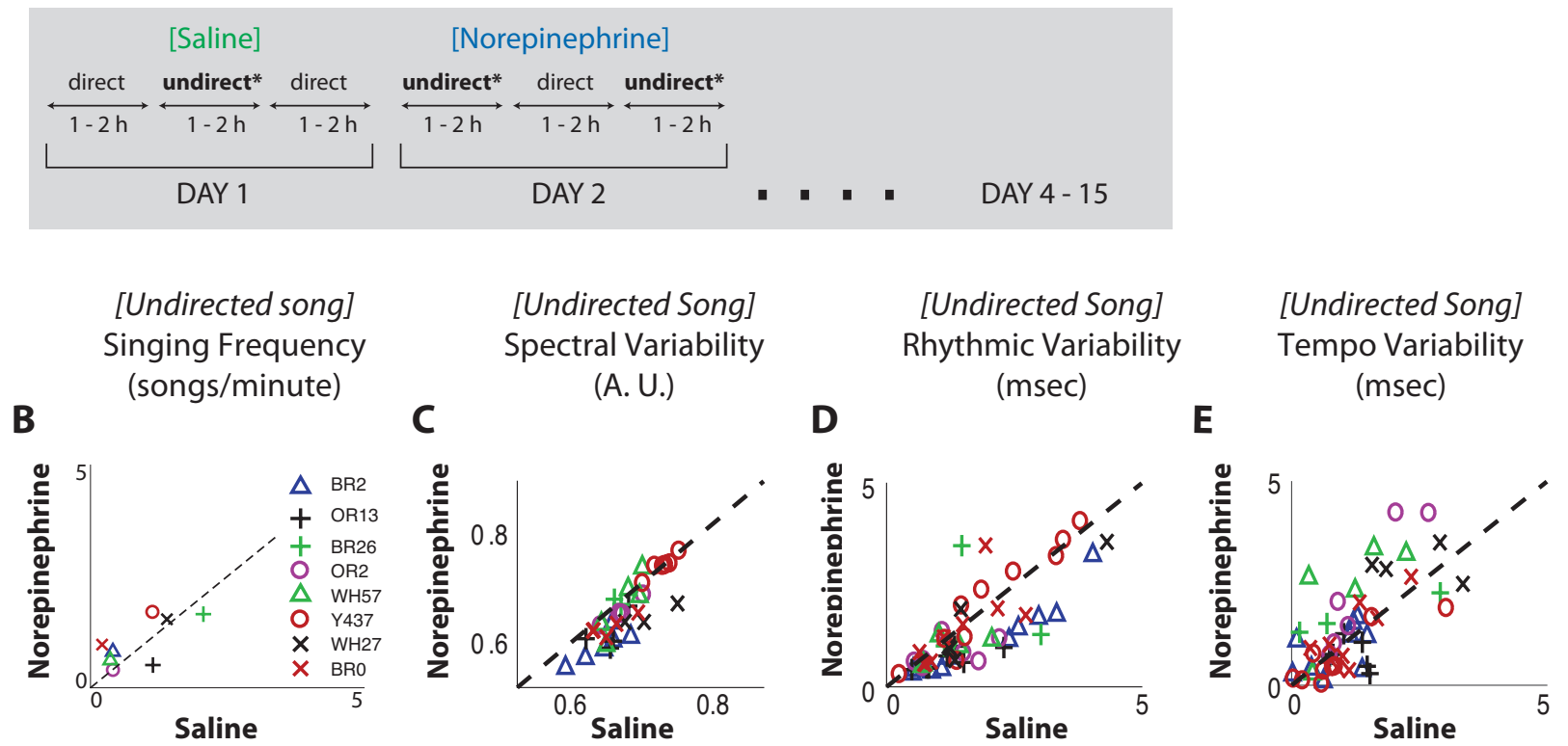
bioRxiv preprint doi: https://doi.org/10.1101/218479; this version posted November 13, 2017. The copyright holder for this preprint (which was not certified by peer review) is the author/funder, who has granted bioRxiv a license to display the preprint in perpetuity. It is made available under aCC-BY 4.0 International license.

\section{FIGURE 6}

A

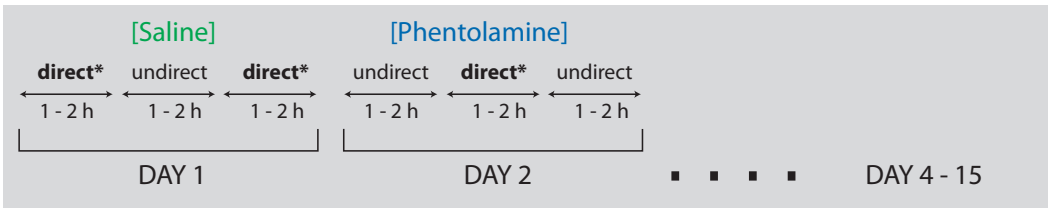

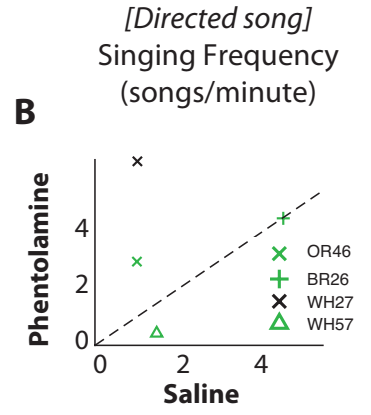

Saline

\section{[Directed song]} Spectral Variability

C

(A. U.)

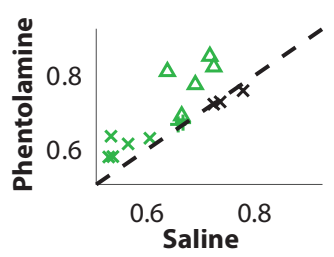

[Directed song] Rhythmic Variability

D

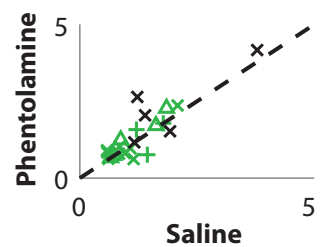

[Directed song] Tempo Variability

E

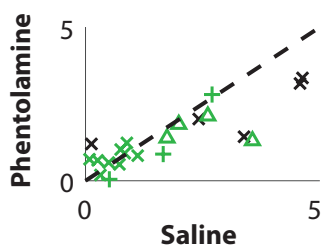


A Singing Frequency (songs/minute)

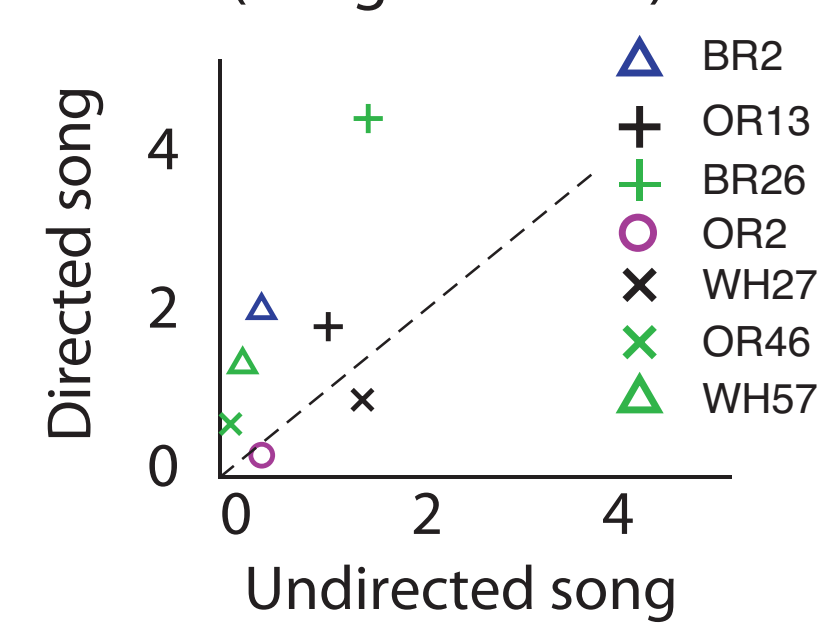

B

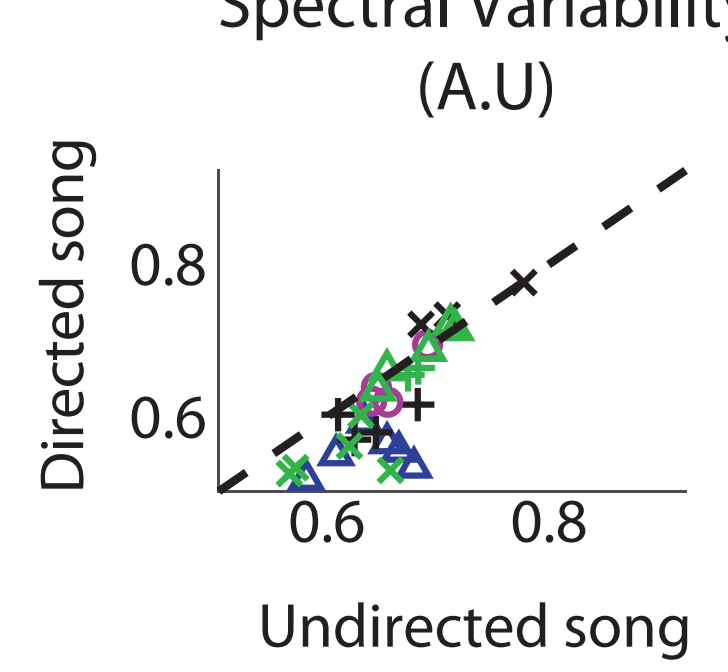

C
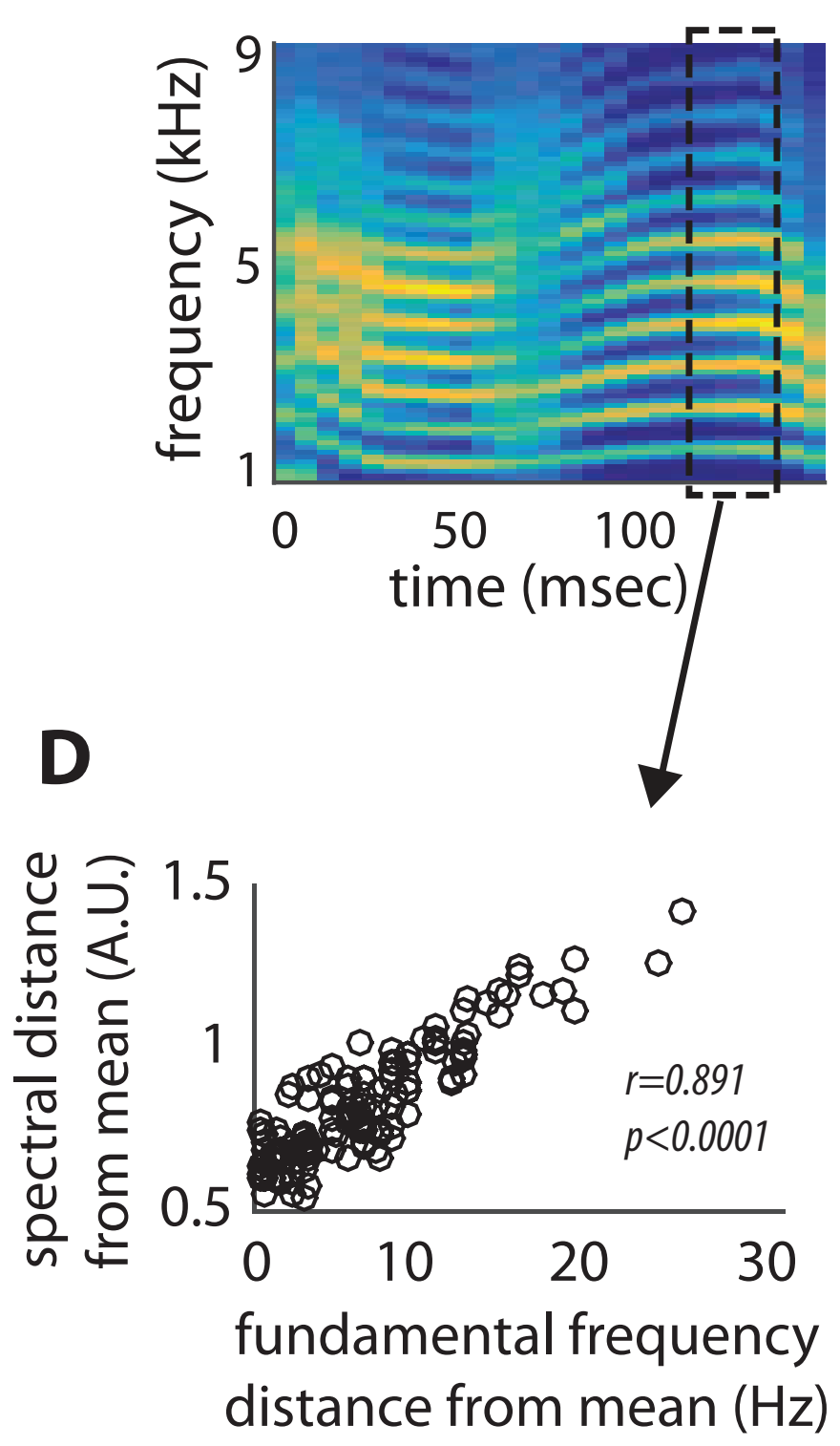

E

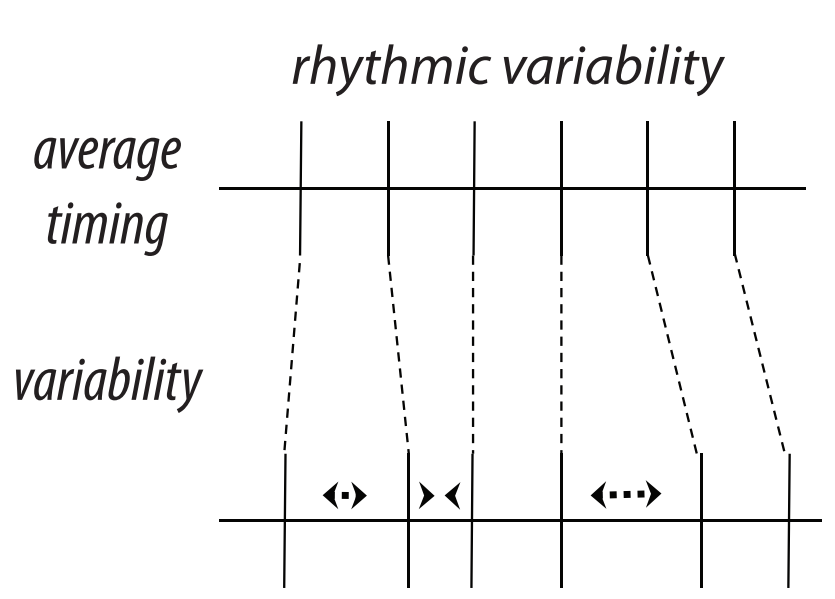

F Rhythmic Variability

(msec)

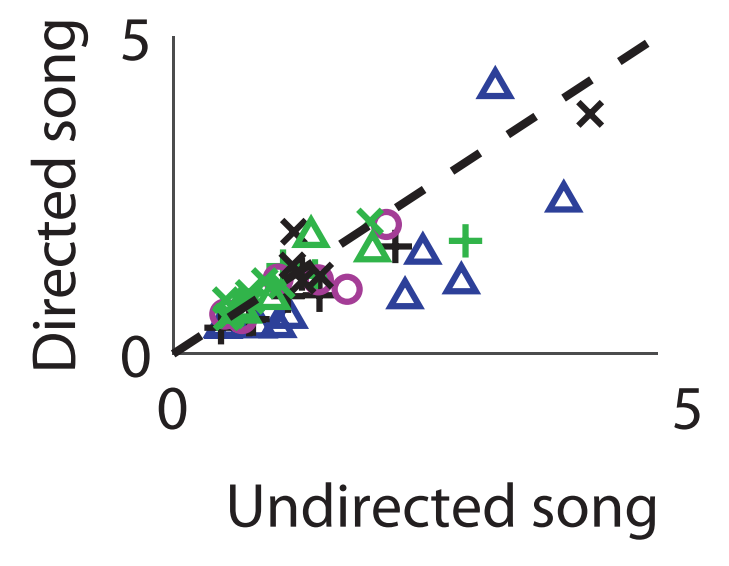

G

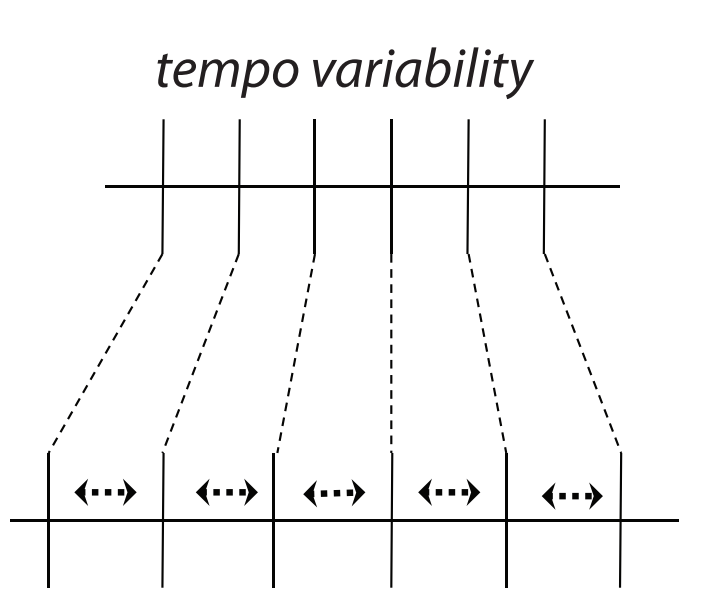

H Tempo Variability (msec)

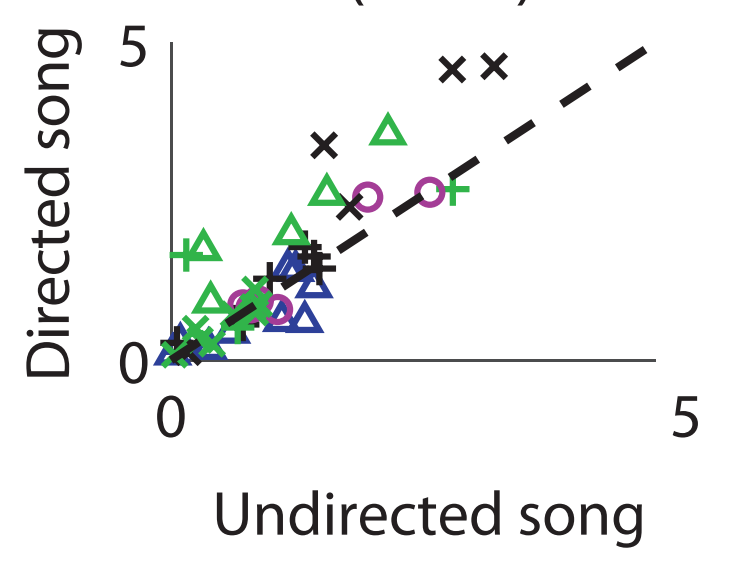

\section{Glaze et al. FIGURE 1}


A

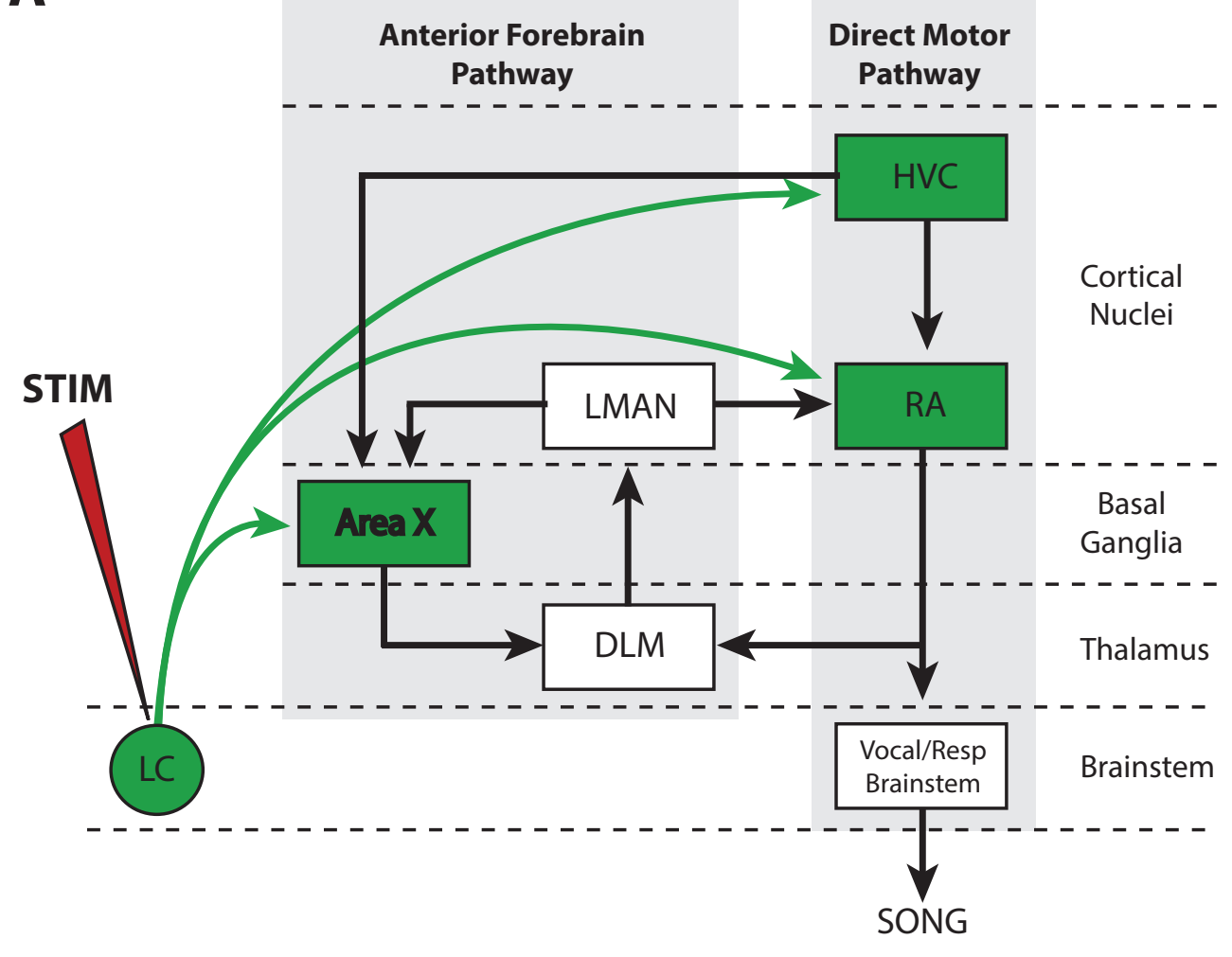

B

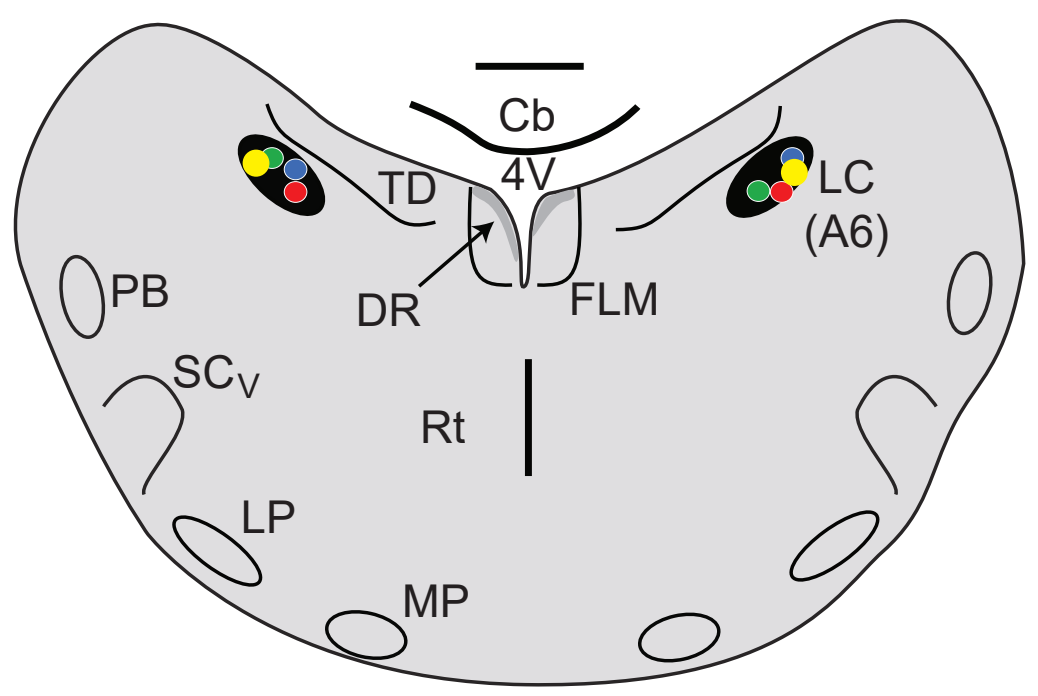




$$
\begin{aligned}
& \text { [undirected song] } \\
& \text { [undirected song] }
\end{aligned}
$$

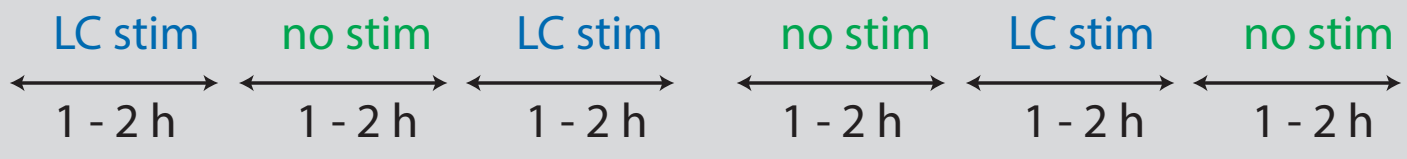

$$
\begin{aligned}
& \text { DAY } 1 \\
& \text { DAY } 2
\end{aligned}
$$

D Rhythmic Variability (msec)

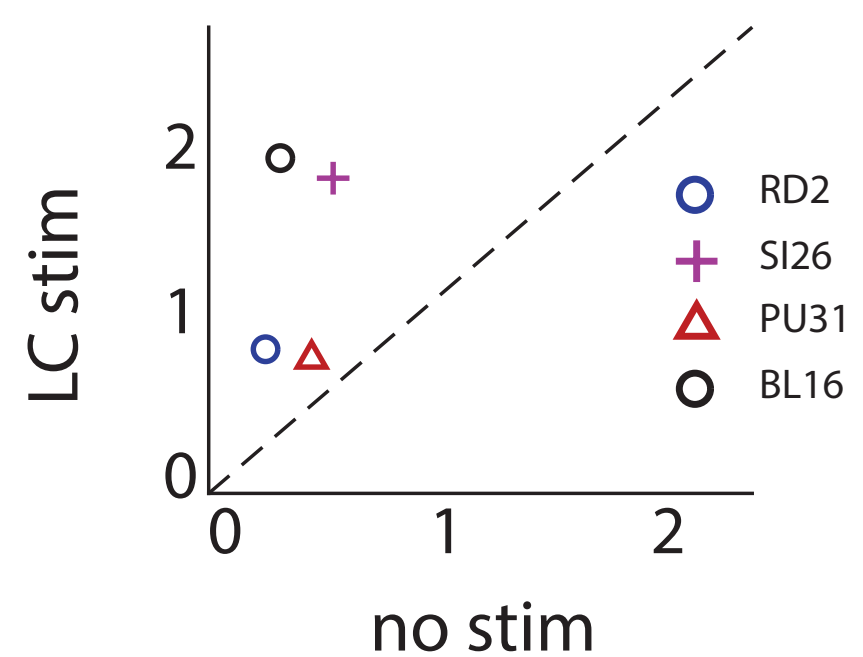

C Spectral Variability (A. U.)

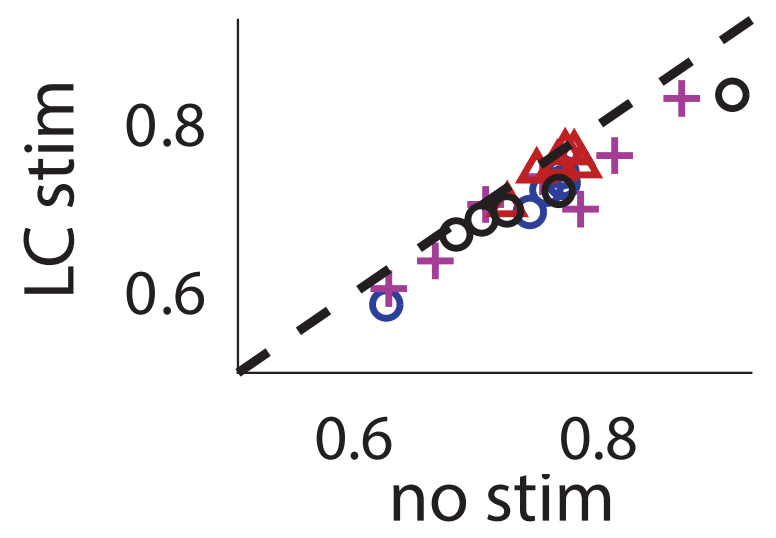

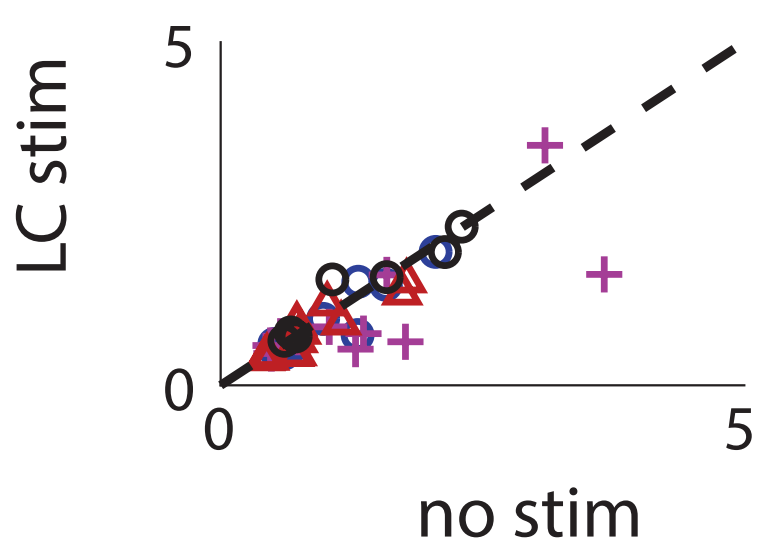

E Tempo Variability (msec)

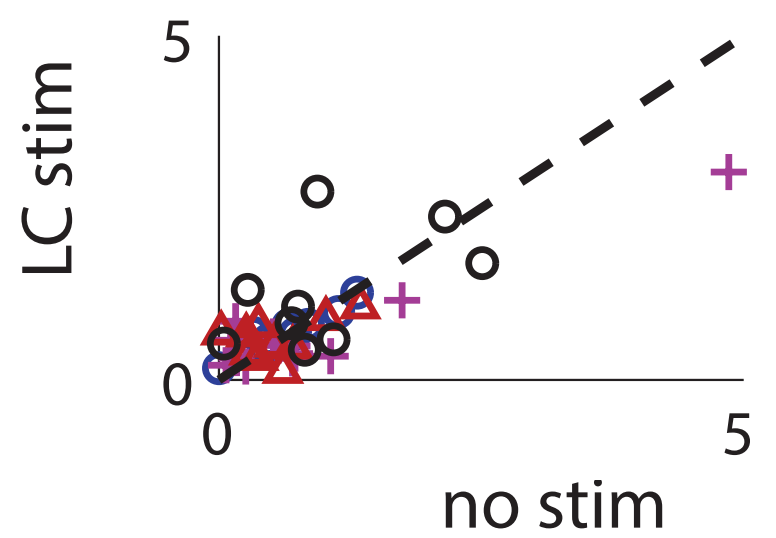


A

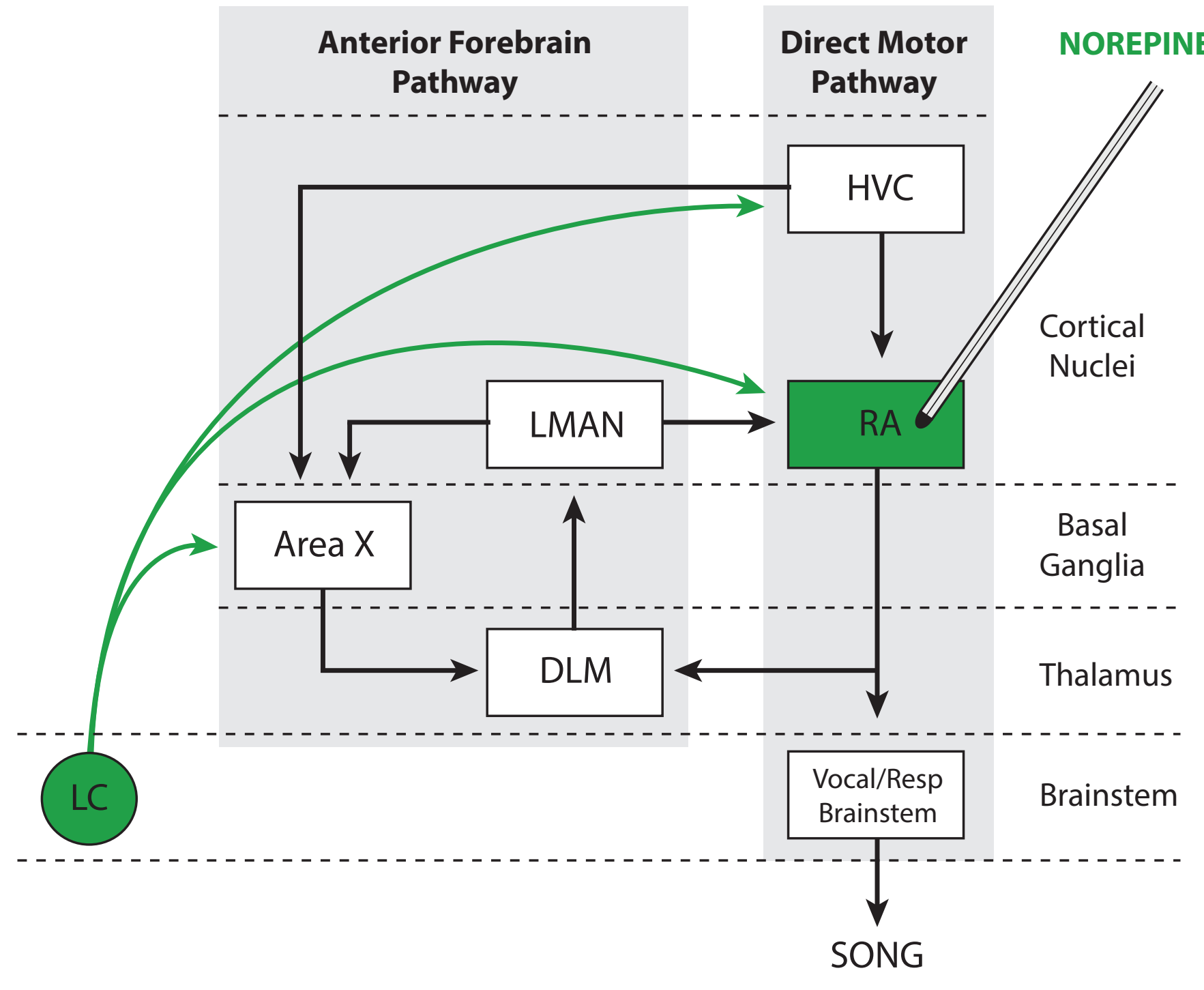

B
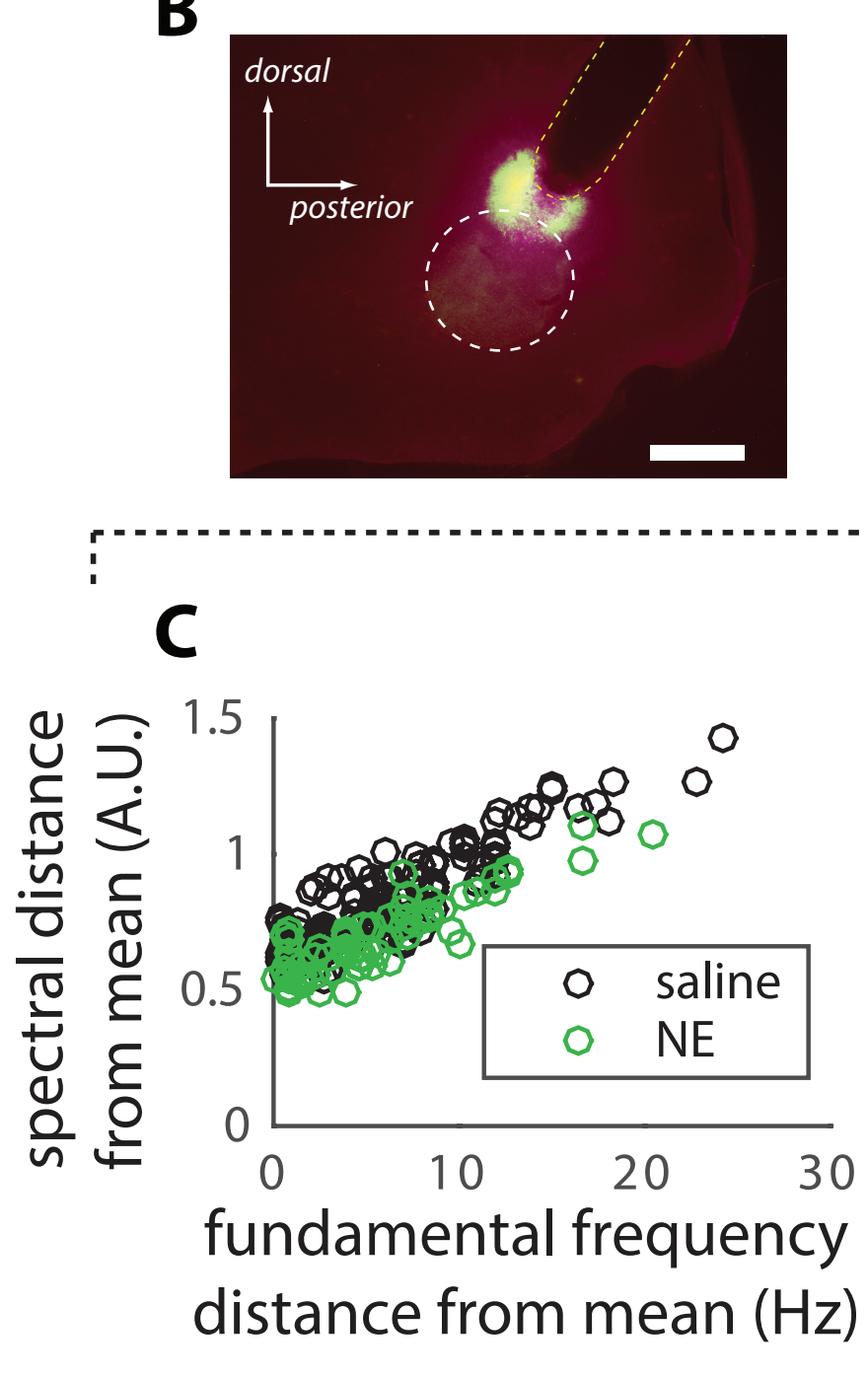

D
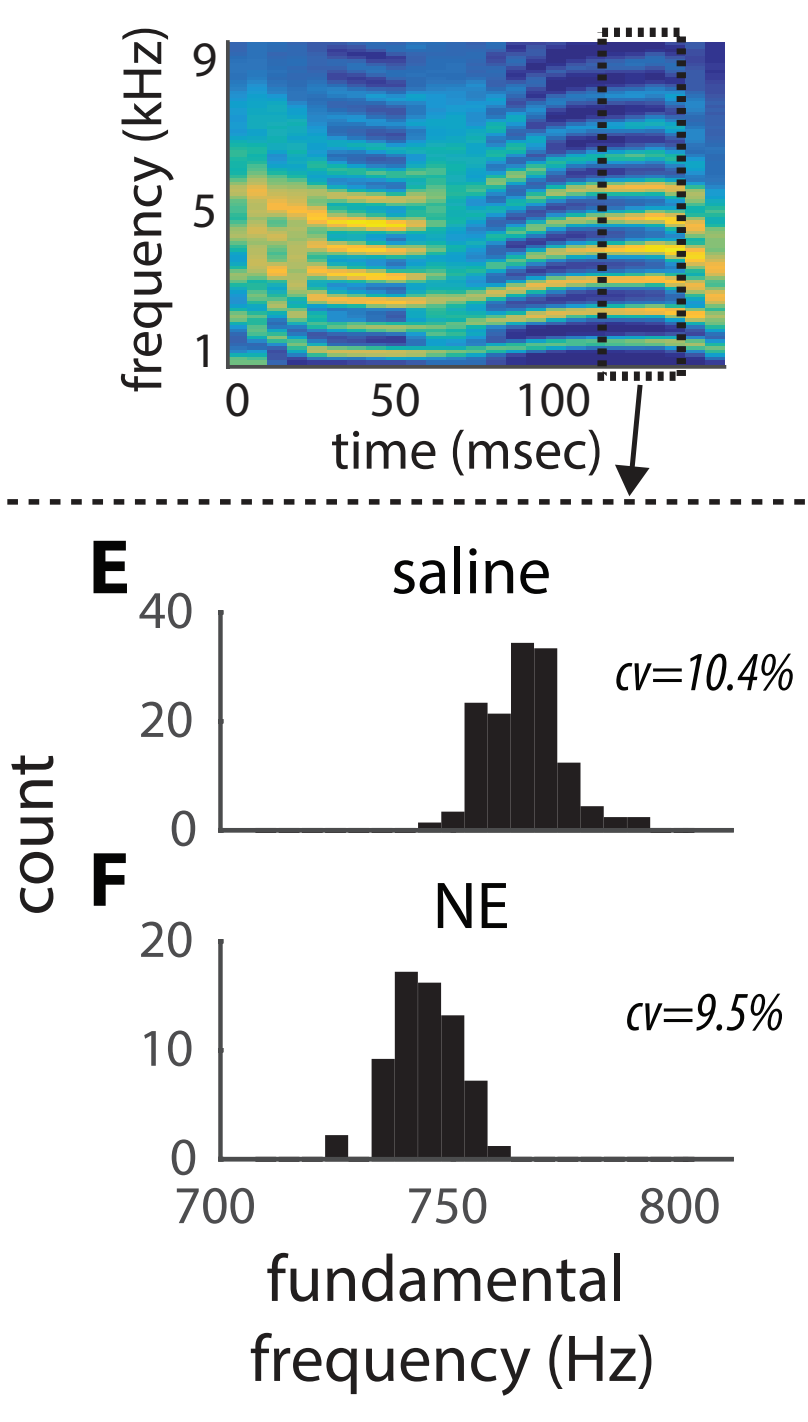
A
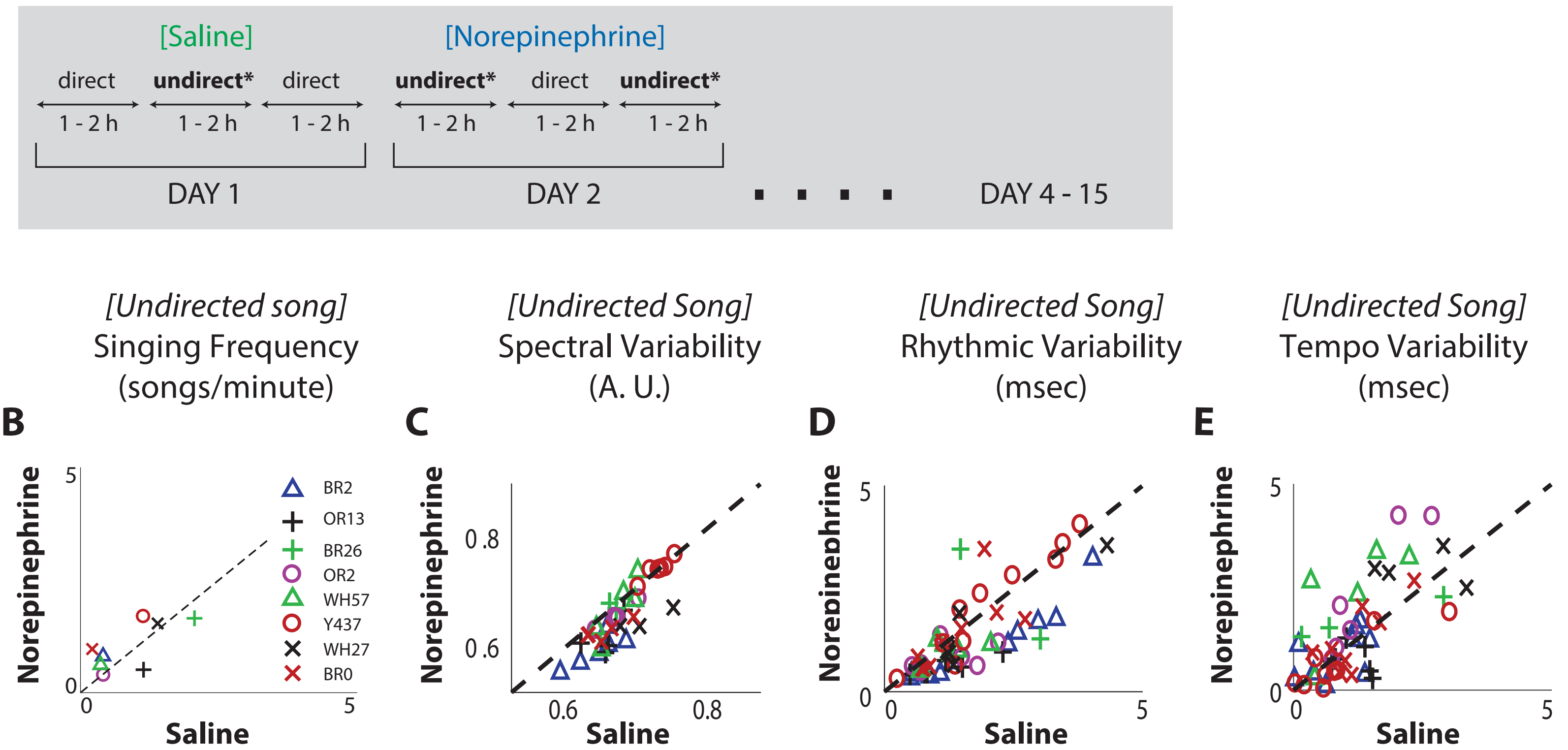

Glaze et al. FIGURE 5 


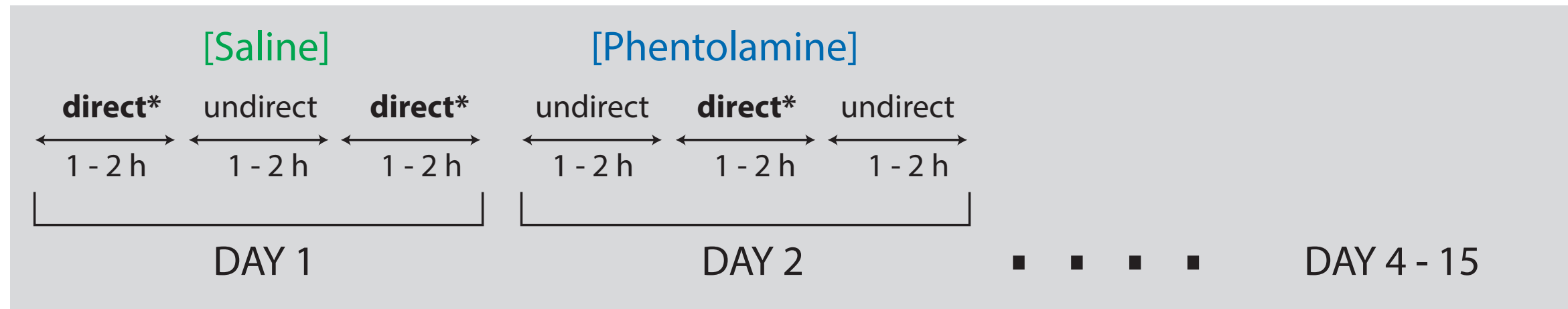
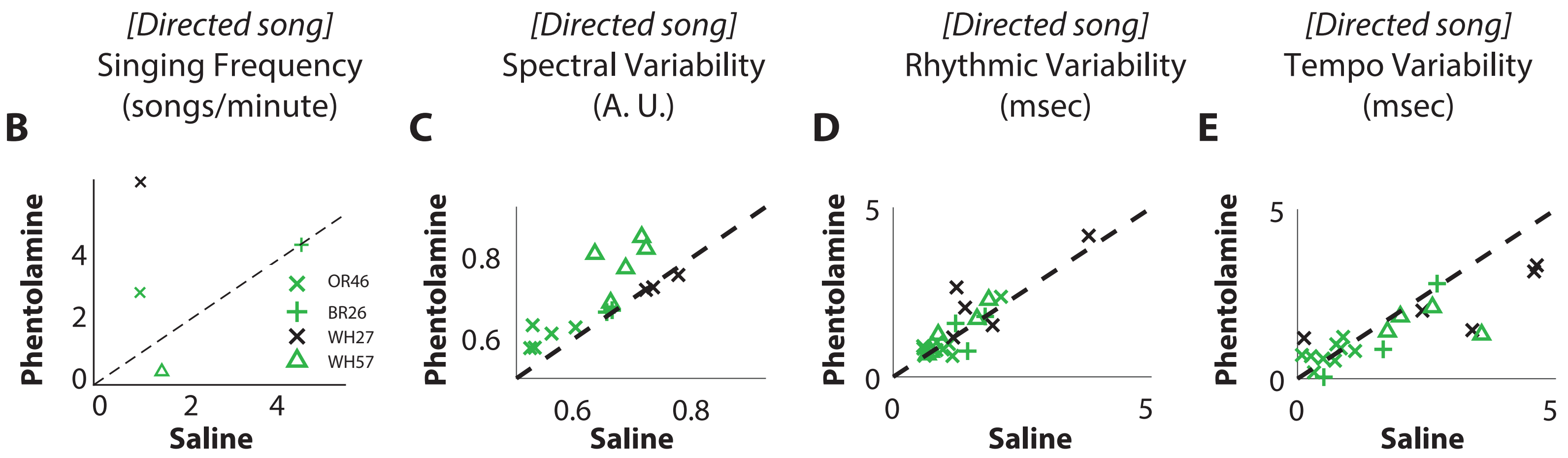

Glaze et al. FIGURE 6 